Article

\title{
Strength and Biocompatibility of Heparin-Based Calcium Phosphate Cement Grafted with Ferulic Acid
}

\author{
Kai-Chi Chang ${ }^{1}$, Jian-Chih Chen ${ }^{2,3}$, I-Tse Cheng ${ }^{1}$, Ssu-Meng Haung ${ }^{1}$, Shih-Ming Liu ${ }^{1}$, Chia-Ling Ko ${ }^{1}$, \\ Ying-Sui Sun ${ }^{4}$, Chi-Jen Shih $5,6,7, * \mathbb{1}$ and Wen-Cheng Chen $1,5,8, * \mathbb{C}$
}

1 Advanced Medical Devices and Composites Laboratory, Department of Fiber and Composite Materials, Feng Chia University, Taichung 407, Taiwan; ketty60221@gmail.com (K.-C.C.); yaschen@fcu.edu.tw (I.-T.C.); dream161619192020@gmail.com (S.-M.H.); 0203home@gmail.com (S.-M.L.); rayko1024.rb@gmail.com (C.-L.K.)

2 Department of Orthopedics, College of Medicine, Kaohsiung Medical University, Kaohsiung 807, Taiwan; d830191@gmail.com

3 Department of Orthopedics, Kaohsiung Medical University Hospital, Kaohsiung 807, Taiwan

4 School of Dental Technology, College of Oral Medicine, Taipei Medical University, Taipei 110, Taiwan; yingsuisun@tmu.edu.tw

5 Department of Fragrance and Cosmetic Science, College of Pharmacy, Kaohsiung Medical University, Kaohsiung 807, Taiwan

6 Drug Development and Value Creation Research Center, Kaohsiung Medical University, Kaohsiung 807, Taiwan

7 Department of Medical Research, Kaohsiung Medical University Hospital, Kaohsiung 807, Taiwan

8 Dental Medical Devices and Materials Research Center, College of Dental Medicine, Kaohsiung Medical University, Kaohsiung 807, Taiwan

check for

updates

Citation: Chang, K.-C.; Chen, J.-C.; Cheng, I.-T.; Haung, S.-M.; Liu, S.-M.; Ko, C.-L.; Sun, Y.-S.; Shih, C.-J.; Chen, W.-C. Strength and Biocompatibility of Heparin-Based Calcium Phosphate Cement Grafted with Ferulic Acid. Polymers 2021, 13, 2219. https:// doi.org/10.3390/polym13132219

Academic Editor: Iolanda De Marco

Received: 21 June 2021

Accepted: 4 July 2021

Published: 5 July 2021

Publisher's Note: MDPI stays neutral with regard to jurisdictional claims in published maps and institutional affiliations.

Copyright: (c) 2021 by the authors. Licensee MDPI, Basel, Switzerland. This article is an open access article distributed under the terms and conditions of the Creative Commons Attribution (CC BY) license (https:// creativecommons.org/licenses/by/ $4.0 /)$
* Correspondence: cjshih@kmu.edu.tw (C.-J.S.); wencchen@mail.fcu.edu.tw (W.-C.C.)

Abstract: The biomimetic synthesis of carbonated apatites by biomolecule-based templates is a promising way for broadening apatite applications in bone tissue regeneration. In this work, heparin was used as an organic template to prepare uniform carbonate-based apatite nanorods (CHA) and graft ferulic acid (F-CHA) for enhanced bone mineralization. Next, by combining calcium phosphate cement (CPC) with different F-CHA/CPC ratios, a new type of injectable bone cement combined with F-CHA bioactive apatite was developed (CPC + F-CHA). The physicochemical properties, biocompatibility, and mineralization potential of the CPC + F-CHA composites were determined in vitro. The experimental results confirmed the preparation of highly biocompatible $\mathrm{CHA}$ and the compatibility of F-CHA with CPC. Although CPC + F-CHA composites with F-CHA $(2.5 \mathrm{wt} \%, 5 \mathrm{wt} \%$, and $10 \mathrm{wt} \%$ ) showed a significant reduction in compressive strength (CS), compositing CPC with $10 \mathrm{wt} \% \mathrm{~F}-\mathrm{CHA}$ yielded a CS suitable for orthopedic repair (CS still larger than $30 \mathrm{MPa}$ ). Spectroscopic and phase analyses revealed that the phase of the hydrothermally synthesized CHA product was not modified by the heparin template. Injection and disintegration tests indicated that the CPC + F-CHA composites have good biocompatibility even at $10 \mathrm{wt} \%$ F-CHA. D1 osteoprogenitor cells were cultured with the composites for 7 days in vitro, and the CPC $+10 \% \mathrm{~F}-\mathrm{CHA}$ group demonstrated significantly promoted cell mineralization compared with other groups. Given these results, the use of over $10 \%$ F-CHA in CPC composites should be avoided if the latter is to be applied to load-bearing areas. A stress-shielding device may also be recommended to stabilize these areas. These newly developed biocompatible CPC + F-CHA have great potential as osteoconductive bone fillers for bone tissue engineering.

Keywords: apatite; nanorods; templates; calcium phosphate bone cement; biocompatibility; mineralization

\section{Introduction}

The composition, structure, and particle size of artificially synthesized carbonatebased apatite nanorods (CHA) are similar to those of natural bone. Moreover, CHA shows 
good biological activity and has an important influence on bone mineralization [1-3]. The $\mathrm{Ca}^{2+}$ and $\mathrm{PO}_{4}{ }^{3-}$ in hydroxyapatite (HA) have the molecular formula $\mathrm{Ca}_{10}\left(\mathrm{PO}_{4}\right)_{6}(\mathrm{OH})_{2}$, which can be replaced by other ions, and the resulting materials can be used in medical devices. For example, the $\mathrm{OH}^{-}$and $\mathrm{PO}_{4}{ }^{3-}$ in apatite can be replaced with $\mathrm{CO}_{3}{ }^{2-}$ to obtain a material with a composition and structure similar to those of bone apatite. The chemical formula of CHA is $\mathrm{Ca}_{10-x}\left(\mathrm{PO}_{4}\right)_{6-x}\left(\mathrm{CO}_{3}\right)_{x}(\mathrm{OH})_{2-x}(0 \leq x \leq 2)$ [3].

The preparation of nano-structured apatite is challenged by issues such as large apatite size distributions, uneven geometric shape distribution, and powder agglomeration during synthesis [3-8]. Therefore, several scholars have sought to determine how to control the growth of apatite crystals precisely and adjust the characteristics of the obtained material to achieve improved mechanical properties and biocompatibility in vivo and in vitro [4]. According to the literature [5], natural glycosaminoglycans, such as heparin and chondroitin sulfate, may be used as templates to control crystal growth. Making the natural organic template as the possible precursor of apatite more worthy of in-depth discussion and research [6]. Besides using CHA to increase the rate of bone formation, some researchers have also used the template to homogenize the formation of nanometerscale apatite, which can be employed to carry drugs to target sites or achieve the slow and sustained release of drugs [7]. Because of the wide applications of CHA, especially CHA nanorods, in the biomedical field, the material has continued to receive extensive research attention $[3,8]$.

Ferulic acid is a stable water-soluble endothelin receptor antagonist. The phenolic hydroxyl group of ferulic acid can reduce oxygen free radicals, thereby reducing damage to cells and tissues. As such, it has gradually attracted the attention of scientists $[9,10]$. Studies have found that, in addition to anti-oxidation and free-radical scavenging effects, ferulic acid also has anti-inflammatory, anti-platelet aggregation, anti-apoptosis, and antiDNA damage properties [9]. Ferulic acid can effectively increase osteopontin after bone matrix mineralization, increase bone growth factors, such as VEGF, TGF- $\beta$, and BMP, and promote local vascular proliferation. Furthermore, it can enhance the activity of osteoblasts and lead to the proliferation, differentiation, and mineralization of these cells. Folwarczna et al. found that ferulic acid participates in the production of osteoblasts through dishevelled (Dsh) and $\beta$-catenin via the Wnt signaling pathway. $\beta$-Catenin controls the main regulator of osteoblasts (i.e., Runx2), promotes osteoblast differentiation, and leads to bone formation [10].

Calcium phosphate bone cement (CPC) is a biocompatible material with fast-curing and self-hardening properties. Therefore, CPC has been widely used in orthopedics and facial bone repair for many years. The diversity of CPCs could be expanded by mixing different types of calcium phosphate with a hardening liquid [11-13]. After the hardening reaction, the main product phases of CPC are apatites, dicalcium phosphate dihydrate (DCPD), and amorphous calcium phosphates (ACP); the products can present as singlephase or multi-phase calcium phosphates. Recent research has attempted to improve the properties of CPCs by endowing them with antibacterial or drug-release properties [14,15]. Functionalized CPC may revolutionize the science of bone repair. CHA nanorods added to the CPC matrix may serve as initial core sites to accelerate the hardening reaction; therefore, nano-sized reinforcements can improve the crystallinity of the CPC after the hardening reaction [16]. The mechanical properties of CPC, especially the osseointegration required for load-bearing applications, can effectively be improved if the appropriate amount of nanoparticles is added to the cement.

In the present study, biomimetically synthesized heparin, an organic template that could regulate the growth of apatite nanorods, was used to react $\mathrm{Ca}^{2+}$ and $\mathrm{PO}_{4}{ }^{3-}$ ions with atmospheric $\mathrm{CO}_{2}[3,17]$. Uniform nanorods of $\mathrm{CHA}$ with heparin were then used as a mediator to graft ferulic acid to form a ferulic acid-based drug template carrier (F-CHA). Next, the carrier was combined with a CPC matrix to form a series of CPC + F-CHA composites. The physical, chemical and mechanical properties of the composites were studied, and the biocompatibility and mineralization potential of the CPC + F-CHA drug- 
impregnated composites was assessed by in vitro cell culture with D1 osteoprogenitor cells. The results of this work provide a preliminary assessment of the future in vivo applications of the developed CPC + F-CHA composites.

\section{Materials and Methods}

\subsection{Materials}

The raw materials used to prepare the CHA nanorods included calcium nitrate $\left(\mathrm{Ca}\left(\mathrm{NO}_{3}\right)_{2}\right.$, Katayama Chemical Industries Co., Ltd., Osaka, Japan) and diammonium hydrogen phosphate $\left(\left(\mathrm{NH}_{4}\right)_{2} \mathrm{HPO}_{4}\right.$, HSE Pure Chemicals, Calgary, AB, Canada). Sodium hydroxide ( $\mathrm{NaOH}$, Shimakyu Pure Chemicals, Osaka, Japan) was used to adjust the solution $\mathrm{pH}$. Heparin (pharmaceutical-grade, Heparin Leo, medical injection for intravenous administration, $25,000-100,000 \mathrm{IU} / \mathrm{mL}$ ) was used as a template to regulate the orientation of CHA and enable the grafting of ferulic acid (Sigma-Aldrich ${ }^{\circledR}$, St Louis, MO, USA) to endow the resultant CHA nanorods with unique functionality. Nondispersive CPC was prepared from tetracalcium phosphate (TTCP)/dicalcium phosphate anhydrous (DCPA) as previously described $[18,19]$. TTCP powder with a mean particle size of $10 \mu \mathrm{m}$ was prepared from the reaction of $\mathrm{Ca}_{2} \mathrm{P}_{2} \mathrm{O}_{7}$ (Alfa Aesar, Johnson Matthey Company, Devens, MA, USA) and $\mathrm{CaCO}_{3}$ (Shimakyu Pure Chemicals, Osaka, Japan). DCPA (CaHPO Organics, Geel, Belgium) with a particle size distribution of $1-3 \mu \mathrm{m}$ and a purity of $98 \%$ was also used.

The cell culture chemicals used in this work included $\alpha$-minimum essential medium $(\alpha$ MEM; Gibco ${ }^{\circledR}$, Thermo Fisher Scientific Inc., Waltham, MA, USA), penicillin/streptomycin (Biological Industries, Kibbutz Beit Haemek, Israel), horse serum (Biolegend Co., San Diego, CA, USA), sodium bicarbonate (Sigma-Aldrich, St Louis, MO, USA), trypsin (Gibco ${ }^{\circledR}$, Thermo Fisher Scientific Inc., Waltham, MA, USA), and dimethyl sulfoxide (DMSO; SigmaAldrich, St Louis, MO, USA). An in vitro toxicology assay kit (XTT, Biological Industries, Kibbutz Beit Haemek, Israel) was also used.

\subsection{Preparation of $C H A, F-C H A$, and $C P C+C H A$ Composites}

CHA nanorods were prepared according to our previously published paper [17]. Briefly, $\mathrm{Ca}\left(\mathrm{NO}_{3}\right)_{2}$ was mixed with 5,10 , or $20 \mathrm{~g}$ of heparin in $100 \mathrm{~mL}$ of aqueous solution and titrated with a solution containing $\left(\mathrm{NH}_{4}\right)_{2} \mathrm{HPO}_{4}$. After titration, the final $\mathrm{Ca} / \mathrm{P}$ atomic ratio in the precipitate system was a stoichiometric $\mathrm{HA}$ value of 1.67 . The suspension was adjusted to $\mathrm{pH} 10$, heat-inactivated at $95^{\circ} \mathrm{C}$ for $4 \mathrm{~h}$ to promote $\mathrm{CHA}$ growth, washed, dried at $60^{\circ} \mathrm{C}$ for $24 \mathrm{~h}$ as $\mathrm{CHA}$ with heparin, and then stored in a dry box to prevent the effects of humidity before further characterization. A transmission electron microscope (TEM, JEOL JEM-2100, JEOL, Tokyo, Japan) was used to examine the powders.

The conditions of F-CHA preparation were as follows. Exactly $0.005 \mathrm{~g}$ of ferulic acid was dispersed in $20 \mathrm{~mL}$ of double-distilled water $\left(\mathrm{ddH}_{2} \mathrm{O}\right)$, mixed uniformly, and then added to $1 \mathrm{~g}$ of $\mathrm{CHA}$ with heparin. The solution was stirred at $25^{\circ} \mathrm{C}$ for $24 \mathrm{~h}$, dried at $40^{\circ} \mathrm{C}$ for $24 \mathrm{~h}$ as F-CHA, and then stored in a dry box.

Various CPC + F-CHA samples were prepared by uniformly mixing CPC powders with different weight percentages $(2.5 \mathrm{wt} \%, 5 \mathrm{wt} \%$, and $10 \mathrm{wt} \%)$ of F-CHA. Hardening solution was added to the above mixture at a liquid-to-powder ratio of $0.6 \mathrm{~mL} / \mathrm{g}$. The properties of the CPC and CPC + F-CHA samples were then compared [18,19].

\subsection{Strength, Injection, and Dispersion Tests}

The CPC composite pastes were filled into a stainless steel mold to form cylindrical specimens measuring $12 \mathrm{~mm}$ in height and $6 \mathrm{~mm}$ in diameter for the compressive strength (CS) test, and disc specimens measuring $3 \mathrm{~mm}$ in thickness and $6 \mathrm{~mm}$ in diameter were prepared for a diametral tensile strength (DTS) and all other cell culture tests. The CS test was conducted following ASTM F 451-99a, and the DTS test was performed following the procedures in [19] by using a desktop universal mechanical tester (LS 500, LLOYD Instruments, Tokyo, Japan) at a crosshead speed of $1 \mathrm{~mm} / \mathrm{min}$. The immersion ratio was set 
to $1 \mathrm{~g}$ of specimen $/ 10 \mathrm{~mL}$ of Tris-buffer saline (TBS), and the specimens were immersed at $37^{\circ} \mathrm{C}$ for $24 \mathrm{~h}$ before measurement. The fracture surfaces of the specimens were examined using a field emission scanning electron microscope (SEM, Hitachi S-3000 N, Hitachi, Tokyo, Japan). The specimens obtained after strength testing were ground for X-ray diffraction (XRD) characterization. An X-ray diffractometer (Shimadzu XRD-6000, Tokyo, Japan) with Ni-filtered $\mathrm{Cu} \mathrm{K} \alpha$ radiation operated at $40 \mathrm{kV}$ and $30 \mathrm{~mA}$ at a scanning speed of $2^{\circ} / \mathrm{min}$ was used.

The injectability and dispersion properties of the CPC + F-CHA composites were tested by injecting the pastes into a large amount of $\mathrm{ddH}_{2} \mathrm{O}$ at $37^{\circ} \mathrm{C}$. Here, the $\mathrm{CPC}+$ F-CHA composite was mixed thoroughly with hardening solution for $1 \mathrm{~min}$ and then filled into a needle-free $3 \mathrm{~mL}$ syringe within $2 \mathrm{~min}$ after starting to mix the pastes. The pastes were then injected into $\mathrm{ddH}_{2} \mathrm{O}$. The dispersion of the pastes after injection into $\mathrm{ddH}_{2} \mathrm{O}$ at different observation times was measured. Table 1 shows the total synthetic component ratios and nomenclature of different groups prepared in this study.

Table 1. Nomenclature of different groups prepared in this work. Pharmaceutical heparin was used as a template to prepare CHA nanorods and graft ferulic acid (F-CHA).

\begin{tabular}{lc}
\hline \multicolumn{1}{c}{ Designated Groups } & Nomenclature \\
\hline Comparative processes without heparin & Control CHA nanorods \\
\hline Templated by heparin LEO INJ 25,000 unit/mL & L25K \\
\hline Templated by heparin LEO INJ 50,000 unit/mL & L50K \\
\hline Templated by heparin LEO INJ 100,000 unit/mL & L100K \\
\hline $\begin{array}{l}\text { Using L25K templated CHA for ferulic acid impregnation } \\
\text { and composite CPC with a ratio of } 2.5 \mathrm{wt} \% \text { L25K/CPC }\end{array}$ & $\mathrm{CPC}+2.5 \%$ F-CHA \\
\hline $\begin{array}{l}\text { Using L25K templated CHA for ferulic acid impregnation } \\
\text { and composite CPC with a ratio of 5.0 wt } \% \text { L25K/CPC }\end{array}$ & $\mathrm{CPC}+5.0 \%$ F-CHA \\
\hline $\begin{array}{l}\text { Using L25K templated CHA for ferulic acid impregnation } \\
\text { and composite CPC with a ratio of } 10.0 \mathrm{wt} \% \mathrm{~L} 25 \mathrm{~K} / \mathrm{CPC}\end{array}$ & $\mathrm{CPC}+10.0 \%$ F-CHA \\
\hline
\end{tabular}

\subsection{In Vitro Measurements}

\subsubsection{Cytotoxicity toward L929 Cells}

The L929 cell line from newborn mouse fibroblasts was provided by the National Institute of Health in Taiwan and used for the cytotoxicity tests. Sample extracts were prepared at a sample-to-medium ratio of $1 \mathrm{~g} / 5 \mathrm{~mL}$. Here, the prepared samples were immersed in the culture medium for $24 \mathrm{~h}$, and the upper layer of the liquid was collected as the extract. Cell viability was determined by culturing the L929 cells in the extracts, and cytocompatibility was determined according to ISO 10993-5:2009. Cells were seeded in a 96-well culture plate in $\alpha$-MEM containing $10 \%$ horse serum culture medium at a density of $1 \times 10^{4}$ cells/well and then cultured overnight. The culture medium was removed, and the extract was added to the L929 cell culture for $24 \mathrm{~h}$. The used cell culture medium was aspirated, and $100 \mu \mathrm{L}$ of new cell culture medium was added to the plates. The extract was aspirated, and afterward, tetrazolium salt (XTT cell proliferation kit; Biological Industries, Israel) was added to $50 \mu \mathrm{L} /$ well and $100 \mu \mathrm{L} /$ well culture medium. The assay is based on the ability of metabolically active cells to reduce the tetrazolium salt XTT to orangecolored compounds of formazan. The intensity of the dye is proportional to the number of metabolically active cells. The plate was incubated in a $5 \% \mathrm{CO}_{2}$ incubator at $37^{\circ} \mathrm{C}$ for $4 \mathrm{~h}$; basically, 2 to $5 \mathrm{~h}$ is usually sufficient according to the instructions. After culture, the viability of the $\mathrm{L} 929$ cells was determined at $\mathrm{OD}_{492}$. The morphological characteristics of the cells were observed under an inverted optical microscope (IX71, Yuan Li Instrument Co., Ltd., Taipei, Taiwan). 
2.4.2. Attachment, Proliferation, and Mineralization of D1 Osteoprogenitor Cell Cultures on Sample Surfaces

Progenitor bone cells (D1) from a bone marrow mesenchymal stem cell line cloned from Balb/C mice were purchased from the American Type Culture Collection. D1 cells were cultured in Dulbecco's modified Eagle medium (DMEM) supplemented with 10\% fetal bovine serum at $37^{\circ} \mathrm{C}$ under a humidified $5 \% \mathrm{CO}_{2}$ atmosphere. The cells were used before their eighth passage.

\section{Cell Attachment and Morphological Observation}

The DTS specimens were cultured with D1 cells at a concentration of $1 \times 10^{4}$ cells/well. The specimens were placed in a 48-well plate, and culture was performed for $1 \mathrm{~h}, 1$ day, or 2 days. The specimens were washed sequentially with PBS, fixed with a mixture of $2.5 \%$ glutaraldehyde and paraformaldehyde, and dehydrated in a gradient alcohol sequence. The specimen was plated with aluminum, and the morphology of the attached cells was observed by SEM.

Semi-Quantitative Detection of Alkaline Phosphatase (ALP) Activity

The ALP test was performed 1, 4, 7, 10, and 14 days after the initial seeding of $1 \times 10^{5} \mathrm{D} 1$ cells on the DTS sample surface of the composites. The culture medium was changed thrice a week. After incubation, the cultured sample was washed with PBS, mixed with a new cell culture medium, and alamarBlue proliferation assay kit to quantitatively measure cell proliferation. After incubation for $4 \mathrm{~h}$, the absorbance of the solution was measured with an ELISA reader at $\mathrm{OD}_{570}$ and $\mathrm{OD}_{595}$. The production of ALP, an early marker of osteogenesis, was determined as follows. The $p$-nitrophenyl phosphatase and TBS in the $p$-nitrophenyl phosphatase kit were added to $20 \mathrm{~mL}$ of sterile water and mixed evenly. After incubation, the cells were washed with PBS once and then added to the prepared solution. The cells were incubated for $30 \mathrm{~min}$, and the absorbance of the cells was measured with an ELISA reader at $\mathrm{OD}_{405}$. The absorbance obtained is proportional to the amount of ALP secreted by the cells.

\subsection{Statistical Analysis}

The results were analyzed using a two-sample $t$-test and an analysis of variance (ANOVA). SPSS Statistics version 20 was employed for all statistical analyses, and Tukey's test was used for post hoc analysis. The two-sample $t$-test compares differences between the averages of two samples, and an ANOVA compares the averages of multiple groups via two different estimates of variance.

\section{Results and Discussion}

\subsection{Identification of $\mathrm{CHA}$}

\subsubsection{XRD Phase Identification}

Comparison of the XRD patterns of the samples with the data of JCPDS No. 046-0905 revealed that the characteristic peaks of CHA correspond to those of apatite planes. This finding indicates that the addition of different concentrations of heparin does not change the hydrothermally synthesized CHA and that the processes described in this work can effectively prepare the CHA phase (Figure 1a). The relative intensities of diffraction peaks corresponding to (002), (211), (112), and (300) show a decreasing trend with the increase in heparin concentration, from L25K to L100k, it is presumed that the crystallinity and size decrease (Table 2). 


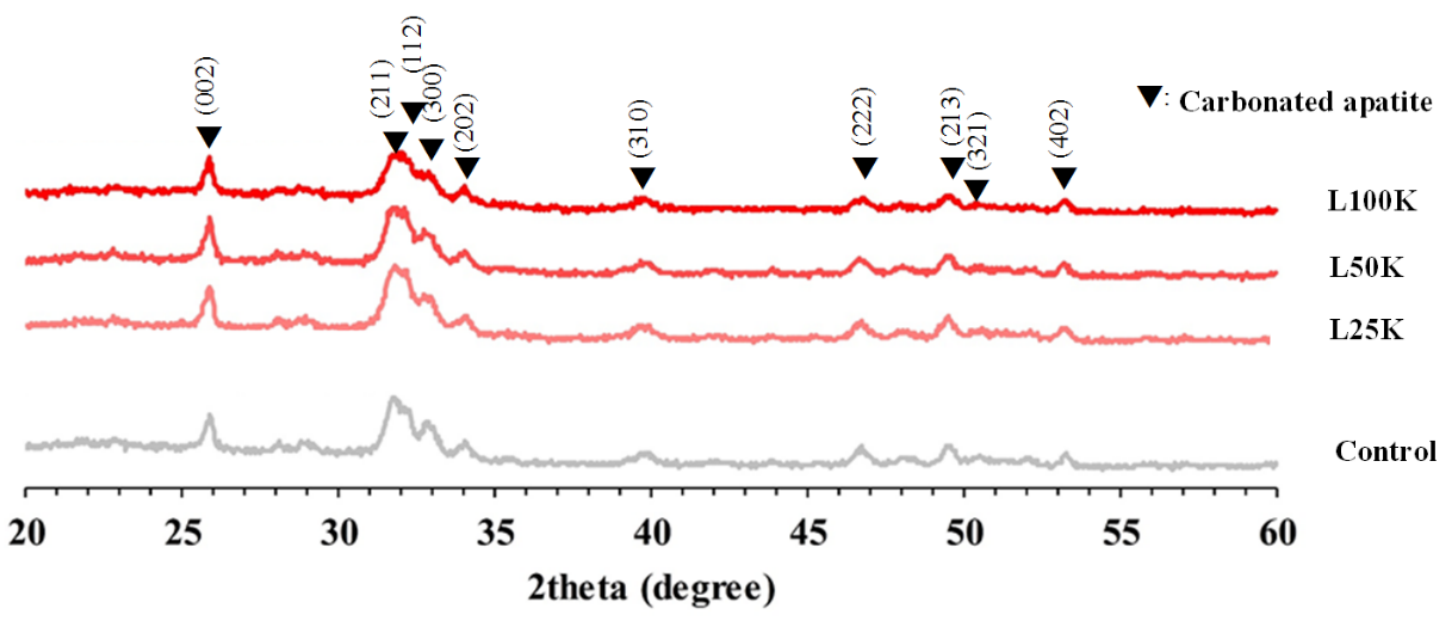

(a)

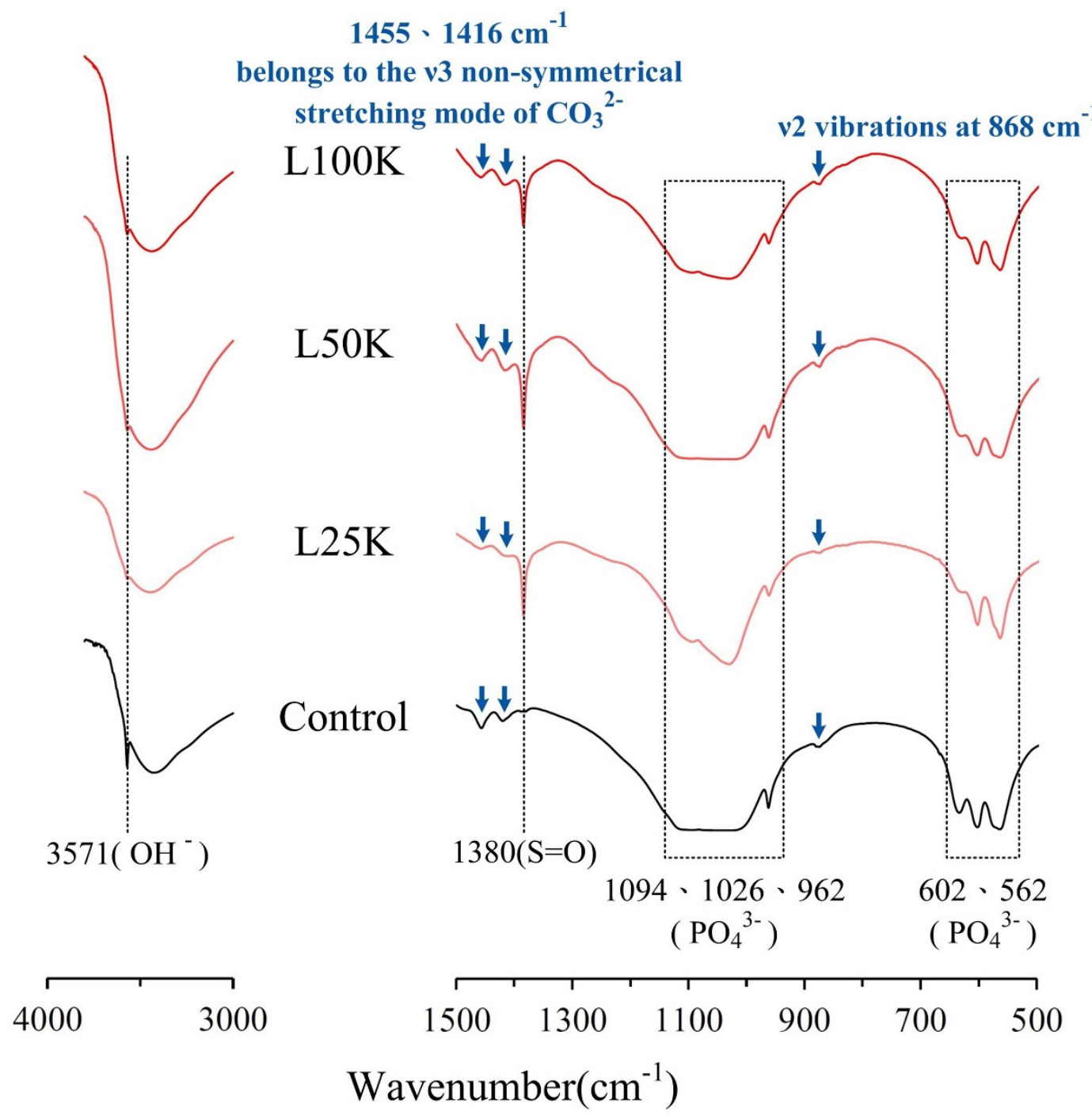

(b)

Figure 1. Cont. 


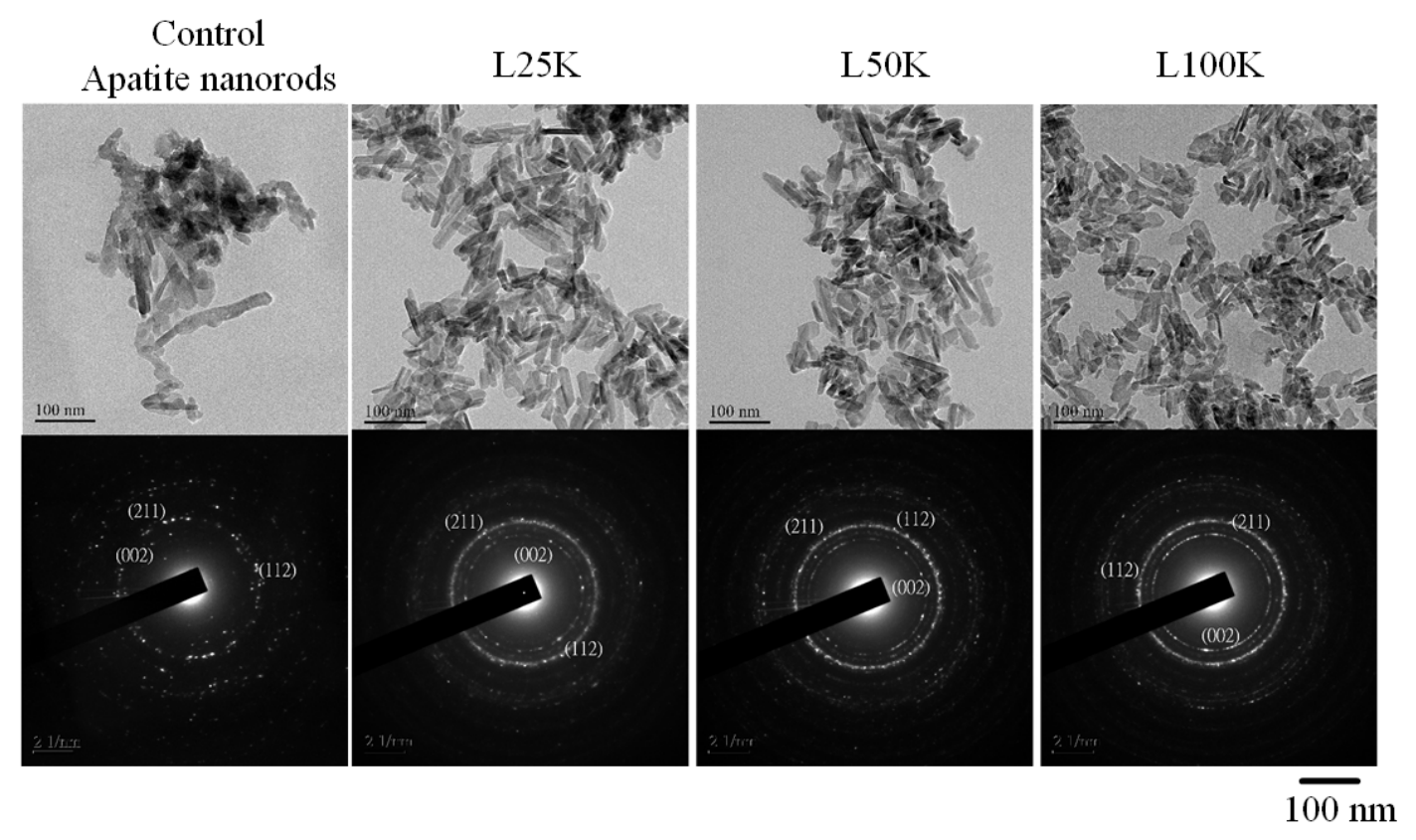

(c)

Figure 1. (a) XRD pattern of carbonated apatite nanorods templated with pharmaceutical heparin and prepared by hydrothermal synthesis. (b) The infrared absorption spectrum of carbonated apatite nanorods templated with pharmaceutical heparin and prepared by hydrothermal synthesis. (c) TEM image of carbonated apatite nanorods templated with pharmaceutical heparin and prepared by hydrothermal synthesis.

Table 2. Average length, width, and the length-to-width ratio of carbonated apatite nanorods templated with different concentrations of pharmaceutical heparin $(n=30)$.

\begin{tabular}{ccccc}
\hline Dimensions and Aspect Ratio & $\begin{array}{c}\text { Control CHA Nanorods } \\
\text { Mean (S.D.) }\end{array}$ & $\begin{array}{c}\text { L25K } \\
\text { Mean (S.D.) }^{\text {a }}\end{array}$ & $\begin{array}{c}\text { L50K } \\
\text { Mean (S.D.) }^{\text {a }}\end{array}$ & $\begin{array}{c}\text { L100K } \\
\text { Mean (S.D.) }^{\text {a }}\end{array}$ \\
\hline Length (nm) & $70.08(28.36)$ & $70.32(20.94)$ & $60.62(21.04)$ & $52.76(8.71)$ \\
\hline Width (nm) & $24.35(6.16)$ & $19.84(5.20)$ & $17.51(3.69)$ & $14.93(6.16)$ \\
\hline Aspect length-to-width ratio & 2.88 & 3.54 & 3.46 & 3.53 \\
\hline
\end{tabular}

\subsubsection{FTIR Spectral Analysis}

The IR spectrum of the CHA product is shown in Figure $1 \mathrm{~b}$. The peak at $3571 \mathrm{~cm}^{-1}$ could be ascribed to the vibrations of the hydroxyl $\left(\mathrm{OH}^{-}\right)$groups, while the peaks at 1094 and $1026 \mathrm{~cm}^{-1}$ correspond to the asymmetric stretching modes of $\mathrm{PO}_{4}{ }^{3-}$. The band at $962 \mathrm{~cm}^{-1}$ is attributed to the symmetric stretching and bending modes of $\mathrm{PO}_{4}{ }^{3-}$ in CHA, and its formula is $\mathrm{Ca}_{10-x}\left(\mathrm{PO}_{4}\right)_{6-x}\left(\mathrm{CO}_{3}\right)_{x}(\mathrm{OH})_{2-x}, 0 \leq x \leq 2$. The bands at 602 and $562 \mathrm{~cm}^{-1}$ represent the bending mode of $\mathrm{PO}_{4}{ }^{3-}$. These two functional groups are derived from the CHA phase $[17,20-22]$. The literature indicates that the absorption bands at 1416 and $1455 \mathrm{~cm}^{-1}$ belong to the $v_{3}$ non-symmetrical stretching mode of $\mathrm{CO}_{3}{ }^{2-}$, as well as $v_{2}$ vibrations at $868 \mathrm{~cm}^{-1}$. This may be due to the increase in carbon content and more substitution of carbonate in the crystal lattice. Thus, type B carbonate substitution occurs in HA $[20,21]$. The majority of calcium phosphate in the precipitation of the thermodynamic reaction in this study, $\mathrm{HA}$, easily combines with $\mathrm{CO}_{2}$ in the atmosphere to form $\mathrm{CHA}$. The results of these analyses demonstrate that the product of this experiment is type $\mathrm{B}$ CHA. In the IR spectrum of the heparin-grafted group, the peak at $1380 \mathrm{~cm}^{-1}$ reflects the asymmetric and symmetric $\mathrm{O}=\mathrm{S}=\mathrm{O}$ stretching vibrations of ester sulfate groups or the deformation vibrations of the $\mathrm{C}-\mathrm{H}$ bond $[17,22]$. This finding confirms that heparin, a 
natural intermediate bridging agent, was indeed grafted on CHA and is involved in the regulation of $\mathrm{CHA}$ growth.

\subsubsection{TEM Images and CHA Nanorod Aspect Ratios}

The TEM results in Figure 1c show that all analyzed groups have (002), (222), and (211) diffraction planes, which agrees with the XRD results. Thus, the synthesized product was confirmed to be CHA $[2,23,24]$. The shape of heparin-free nanorods is irregular and different in size; by comparison, the experimental groups with heparin as a template are shaped like nanorods. As the concentration of heparin increased, the CHA nanorods became thinner and shorter. Table 2 shows that the length of CHA nanorods between the non-template control and the L100K template group, as well as that between the L25K and L100K template groups, are significantly different $(p<0.05)$. Moreover, compared with those of the L50K and L100K groups, the diameter of CHA nanorods in the control group was significantly different $(p<0.05)$.

\subsubsection{Cytotoxicity of CHA}

The biocompatibility test revealed that only the L100K group has cytotoxicity (Figure 2). The control, L25K, and L50K groups revealed no cytotoxicity. Since hydroxyapatite nanoparticles are formed through a combination of chemical synthesis pathways and cell dependence, cytotoxicity depends on their shape [3,25]. The analysis results showed that the biocompatibility of the L25K group is similar to other groups except for L100K, and no cytotoxicity was detected. Due to the heparin concentration playing an important factor in the chemical constitution and morphology, as well as biological properties of CHA, a higher concentration of heparin might lead to more $\mathrm{CO}_{2}$ absorption and thus lower the $\mathrm{Ca} / \mathrm{P}$ ratio [21]. The morphology of CHA was small (Figure 1c) and the substitution of carbonate can enhance the solubility of CHA with a lower Ca/P ratio in a group of L100K compared to other groups of control CHA, L25K, and L50K. In addition, a large amount of soluble $\mathrm{CHA}$ with lower $\mathrm{Ca} / \mathrm{P}$ tends to make the medium more acidic than $\mathrm{CHA}$ with higher $\mathrm{Ca} / \mathrm{P}$, resulting in poor biocompatibility. Among the groups tested, the L25K group demonstrated the most consistent morphology (i.e., the most uniform nanorods). Therefore, in subsequent experiments, $\mathrm{L} 25 \mathrm{~K}$ was compounded with CPC to evaluate the effect of F-CHA on the cell mineralization potential of D1 progenitor cells.

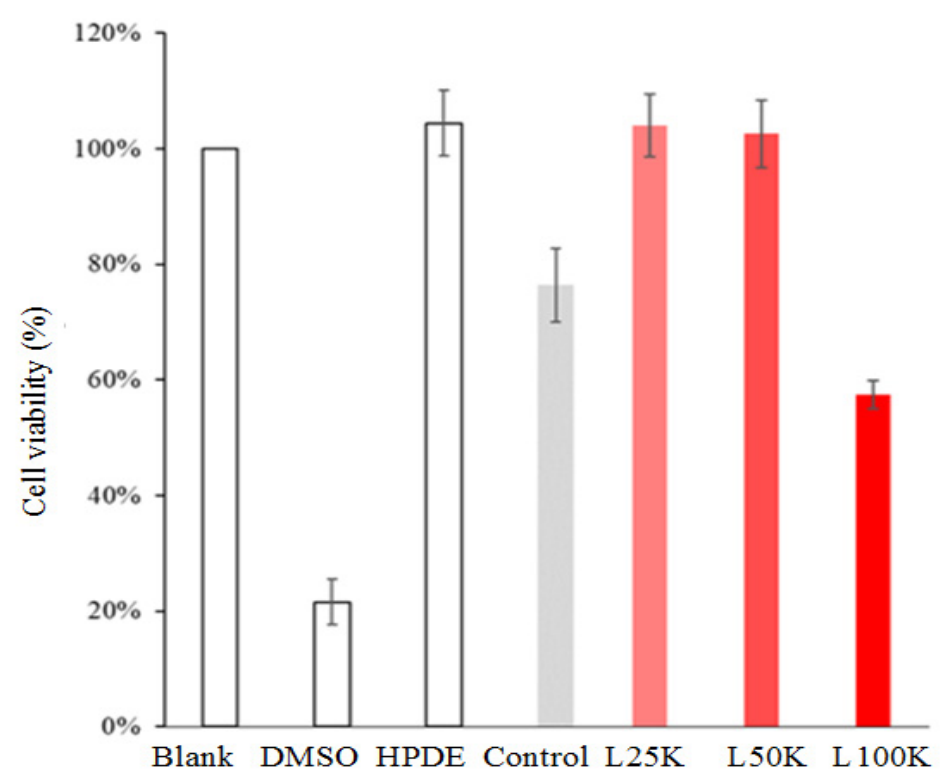

Figure 2. Viability of L929 cell cultures exposed to different extracts of CHA nanorods templated with different concentrations of pharmaceutical heparin $(n=6)$. 


\subsection{Identification of F-CHA and the Corresponding Templating Mechanism}

The XRD patterns of F-CHA showed an overlap of the characteristic peaks of CHA and FA. This finding indicates that ferulic acid was successfully impregnated into CHA (Figure 3a). FTIR spectral analysis of the impregnated ferulic acid showed that in addition to the stretching and bending modes of $\mathrm{PO}_{4}{ }^{3-}$ from $\mathrm{CHA}$, a functional group different from CHA could be detected at $1384 \mathrm{~cm}^{-1}$. Comparison with the literature data [9] indicates that this band is the vibration peak of ferulic acid C-H (Figure 3b). The FTIR and XRD results are consistent and confirm that CHA was successfully impregnated with osteogenesispromoting ferulic acid.

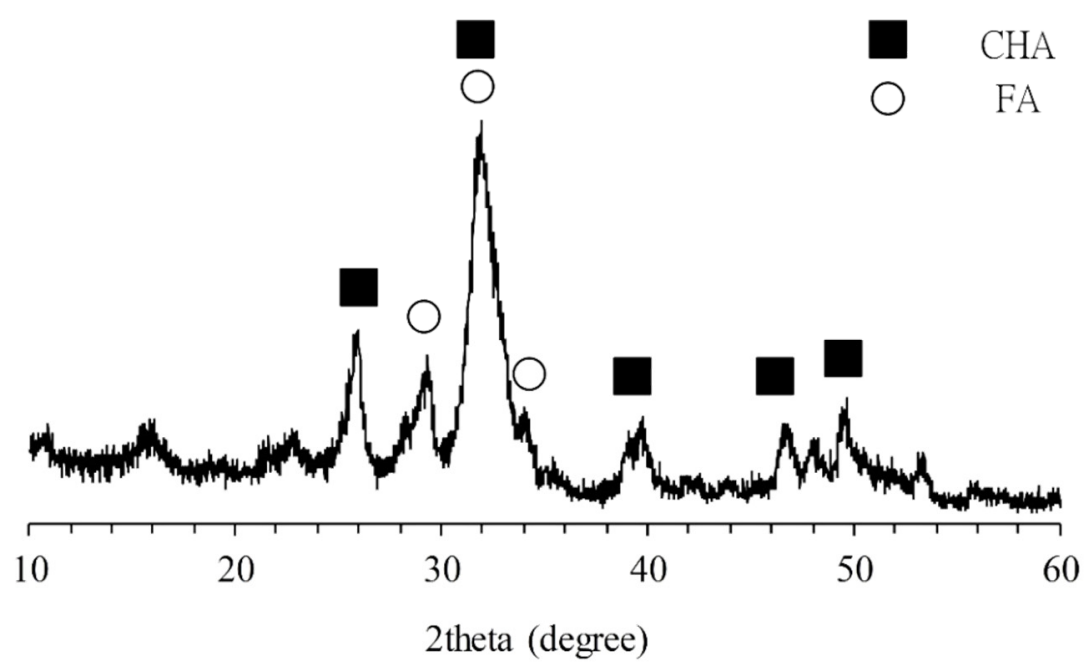

(a)

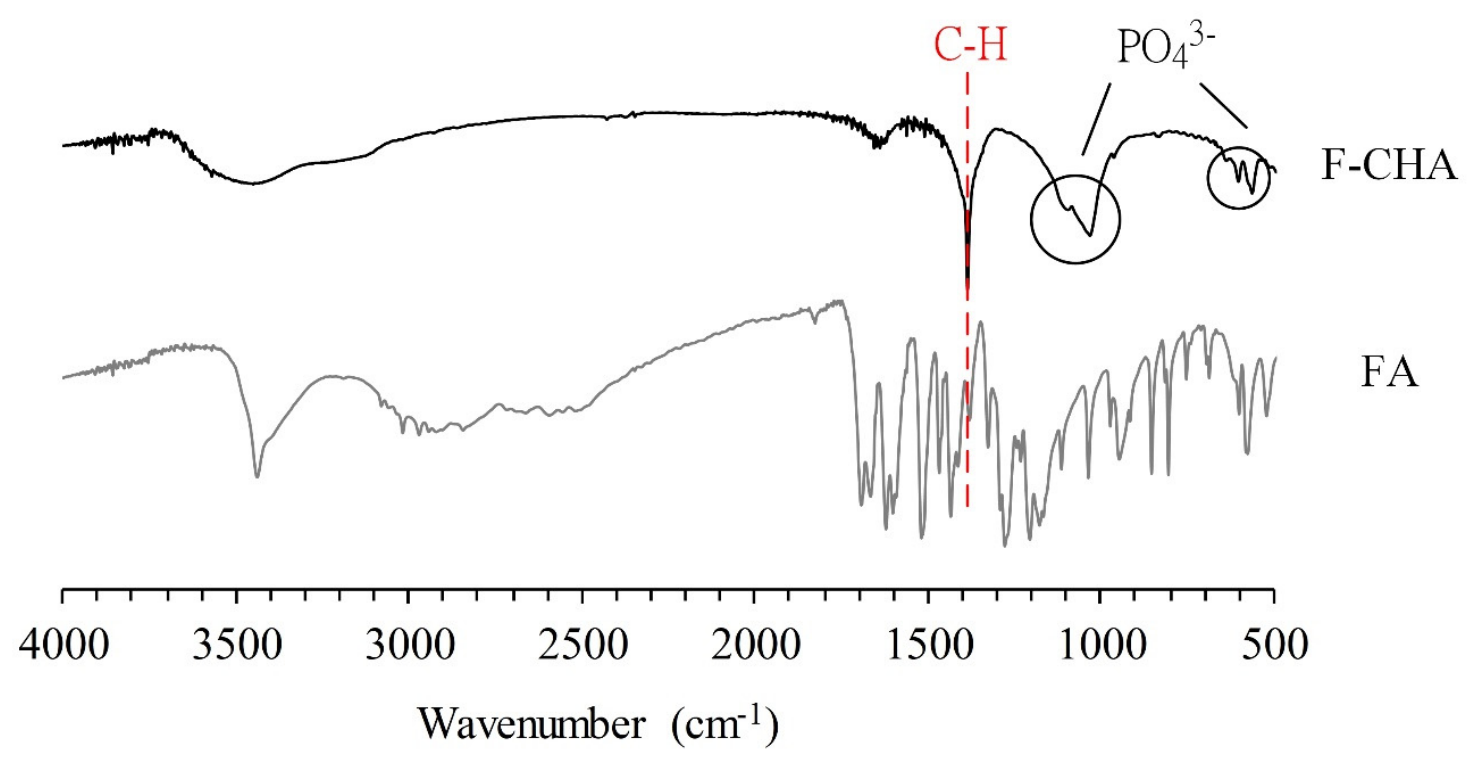

(b)

Figure 3. XRD pattern (a) and IR spectrum (b) of heparin-templated CHA nanorods impregnated with ferulic acid (F-CHA).

In this study, heparin was used as an intermediate branching agent to regulate the growth of CHA nanorods and template to bind ferulic acid. The relevant mechanism may involve (1) the reaction of $\mathrm{Ca}^{2+}$ and $\mathrm{PO}_{4}{ }^{3-}$ with $\mathrm{CO}_{2}$ in a hydrothermal environment with heparin as a mediator to precipitate uniformly shaped CHA and (2) the use of the 
intermediate as a template to adsorb ferulic acid and promote the formation of F-CHA nanorods. A schematic of the possible reaction mechanism is shown in Figure 4.

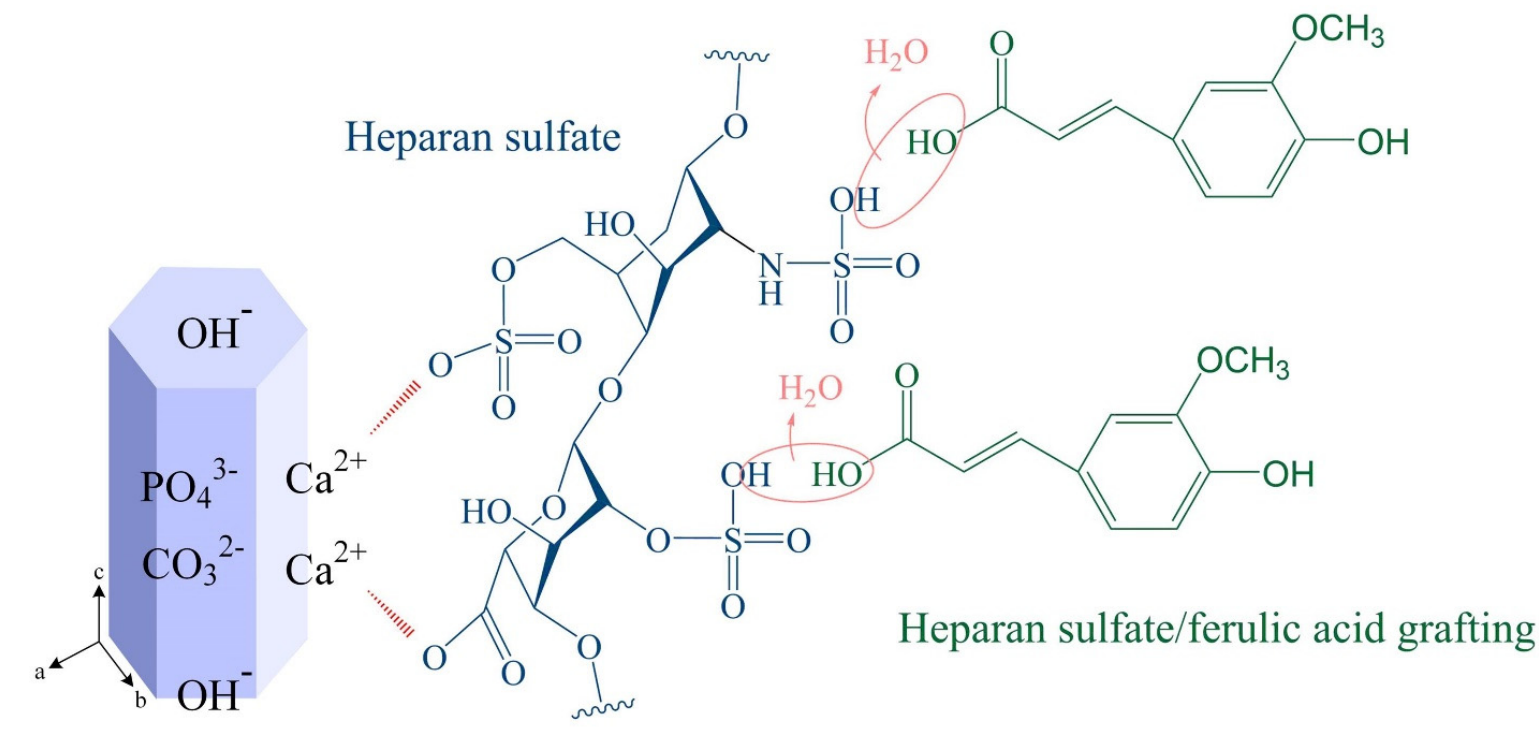

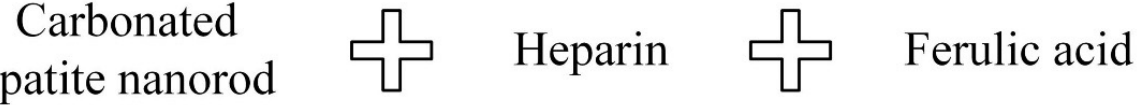

Figure 4. Possible grafting mechanism of polarized heparin-templated carbonated apatite nanorods grafted with ferulic acid.

Therefore, the carboxyl, carbonyl, and sulfate of the template heparin are thought to trigger the nucleation of apatite, thereby regulating $\mathrm{CHA}$ nucleation from the early stage. In the biomimetic manufacturing of apatite hybrid materials, the bi-molecular template is binding with ferulic acid through the polarized heparin template $\mathrm{CHA}$, and the combination of molecules reduces the polarization charge of the original $\mathrm{CHA}$. The interaction between CHA nanoparticles using heparin as a template and binding ferulic acid can improve this kind of nanoparticles with polarized charge-induced CHA aggregation (Figure 1c).

3.3. Release Characteristics, Strength, Phase, Morphology, and Injectability of CPC $+F-C H A$ 3.3.1. Individual Time and Cumulative Release Characteristics of Ferulic Acid

The results of the drug release tests indicated that ferulic acid has a characteristic absorption peak at $\mathrm{OD}_{313}$ in the UV/Vis spectrum. Each group of $\mathrm{CPC}+\mathrm{F}-\mathrm{CHA}$ composites was immersed in deionized water for different times and then measured to determine the individual (Figure 5a) and cumulative (Figure $5 b$ ) release characteristics of ferulic acid. The individual release curves revealed two obvious release peaks for each group (Figure 5a). The first peak release occurred within $1 \mathrm{~h}$ and may be attributed to the initial burst release of ferulic acid on the surface of the CPC + F-CHA composites. The second gentle release peak was observed between $4 \mathrm{~h}$ and 3 days, which may be caused by the slow cumulative release of ferulic acid in the CPC composite. This phenomenon was confirmed by the cumulative release curves (Figure $5 b$ ). Ferulic acid was released in large quantities before 1 day and then demonstrated stable and sustained-release mode after 2 days. The results of these tests indicate that ferulic acid is released in three stages. The first stage is a burst early release that occurs within $1 \mathrm{~h}$ and is speculated to reflect the release of ferulic acid from the surface of the CPC + F-CHA composites. The second stage is an extensive release that occurs from $4 \mathrm{~h}$ to 3 days, which could be attributed to the diffused release of ferulic acid within the composites. Finally, the third stage is a slow-release that occurs after 3 days. These findings confirm that F-CHA may be an effective drug carrier. 


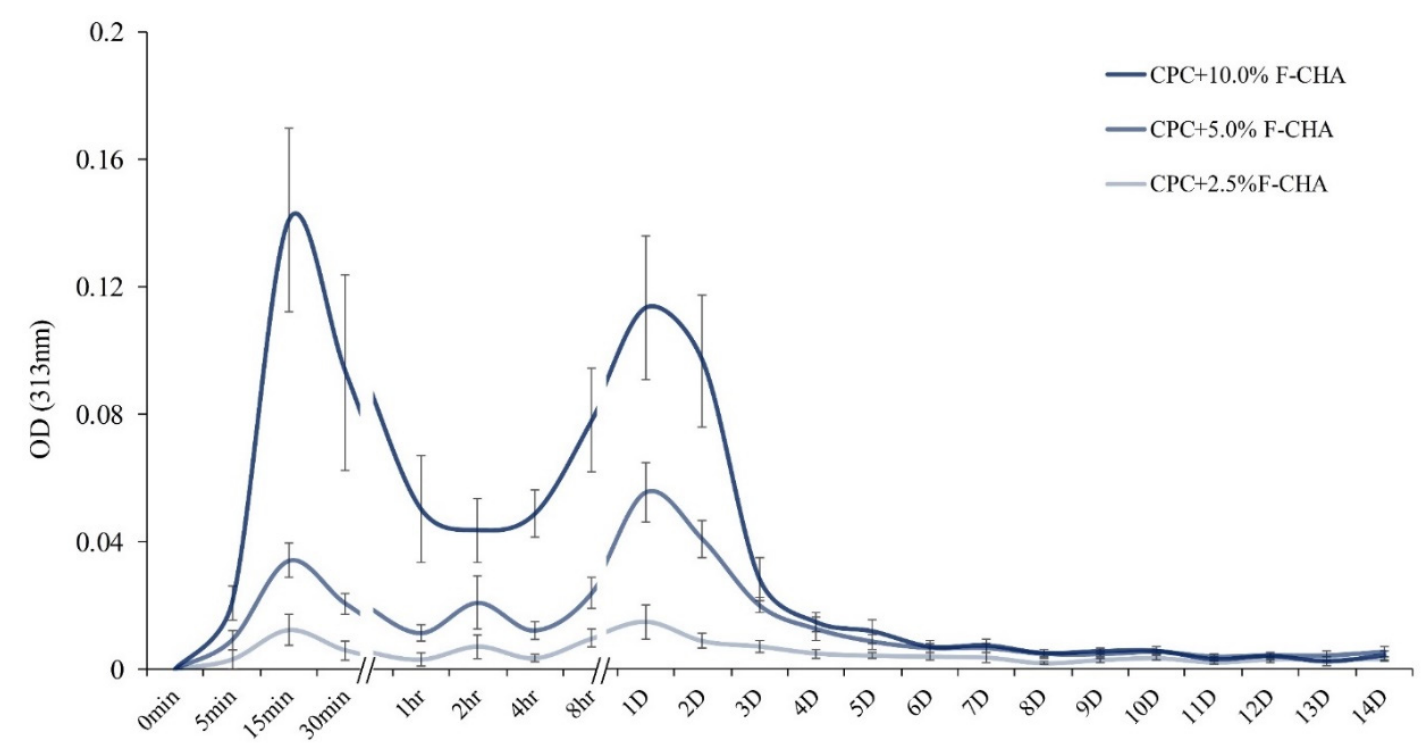

(a)

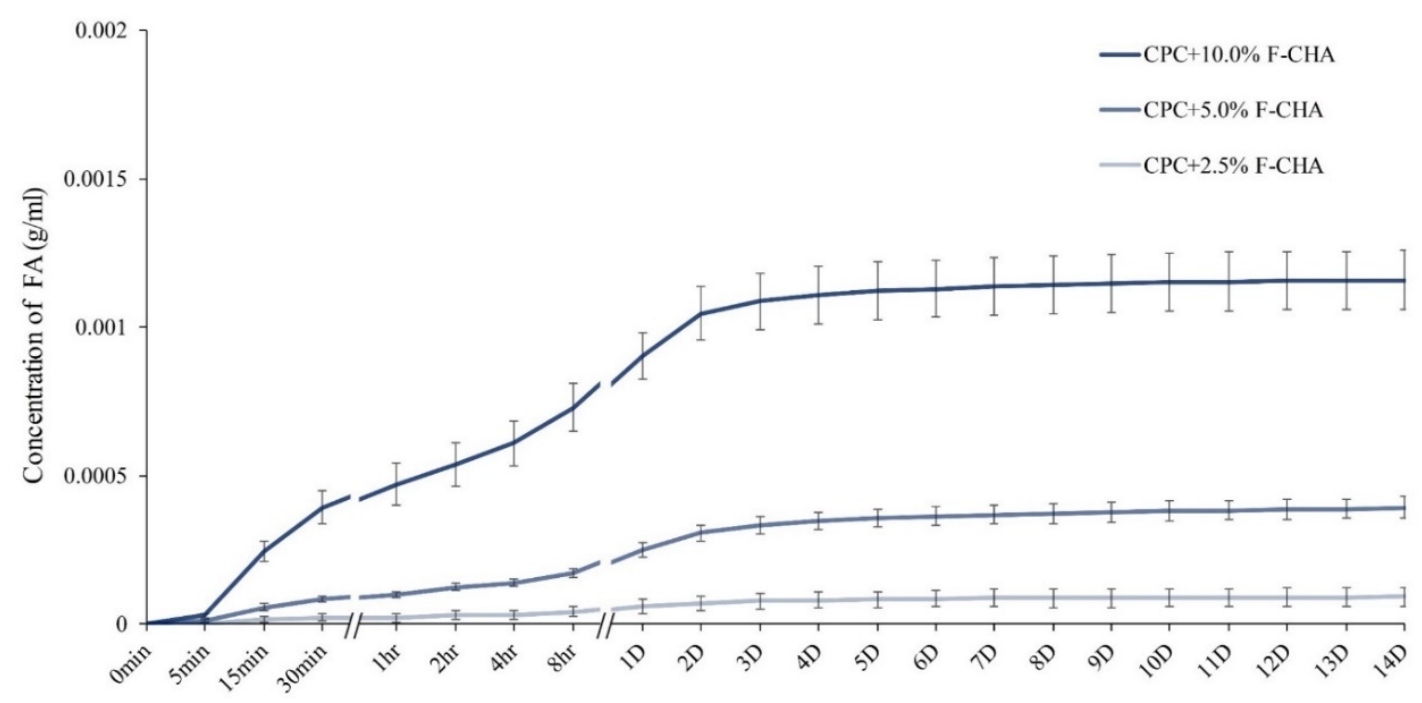

(b)

Figure 5. Individual time-release plots of ferulic acid (a) and cumulative release of carbonated apatite nanorods impregnated (b) with different concentrations of ferulic acid after immersion in $\mathrm{ddH}_{2} \mathrm{O}$. The phenomenon of double-release peaks could be observed $(n=5)$.

\subsubsection{Compressive and Diametral Tensile Strengths of CPC + F-CHA Composites}

The strength of ideal bone implants should be comparable with that of human trabecular bone. The maximum CS of human trabecular bone is $30 \mathrm{MPa}$, and this standard can be used to evaluate whether experimental samples meet clinical needs [26]. The CS test results are shown in Figure 6a. The average CS of the CPC control after immersion in TBS for 1 day was $79 \mathrm{MPa}$. The addition of F-CHA revealed a decrease in CS. While no significant difference in the strengths of $\mathrm{CPC}+2.5 \% \mathrm{~F}-\mathrm{CHA}$ and $\mathrm{CPC}+5.0 \% \mathrm{~F}-\mathrm{CHA}$ was noted, the CS of the CPC $+10.0 \% \mathrm{~F}-\mathrm{CHA}$ group was significantly poorer than that of these groups. The remaining average test value of CS was only $31 \mathrm{MPa}$. Figure $6 \mathrm{~b}$ illustrates the DTS of each group of CPC + F-CHA composites. In general, the trend of the DTS of the composites was consistent with that of their CS. 


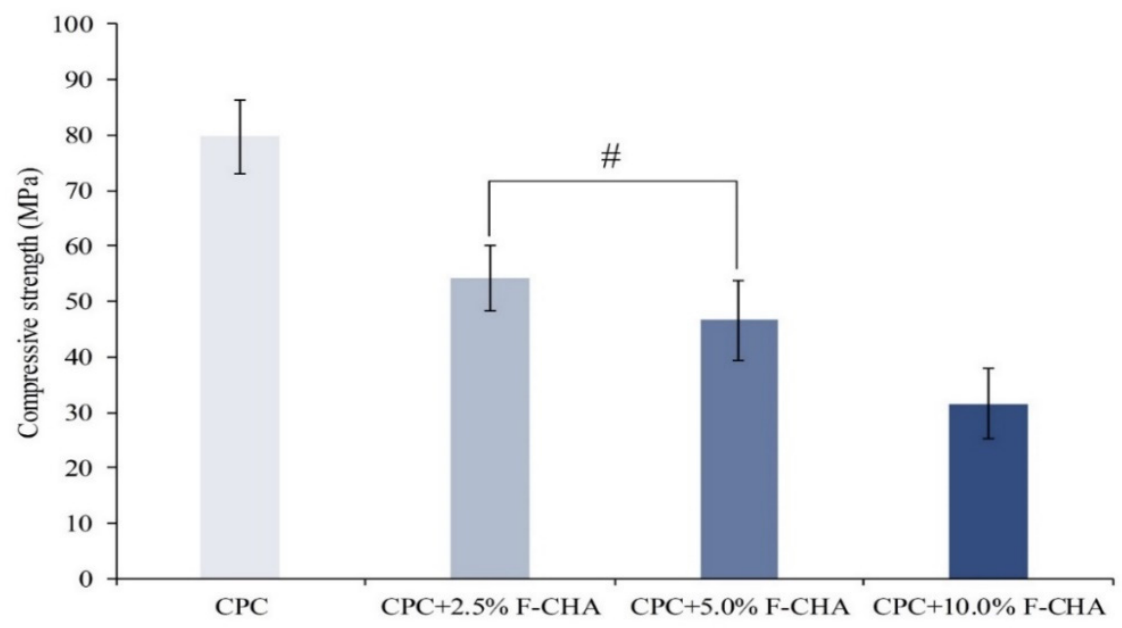

(a)

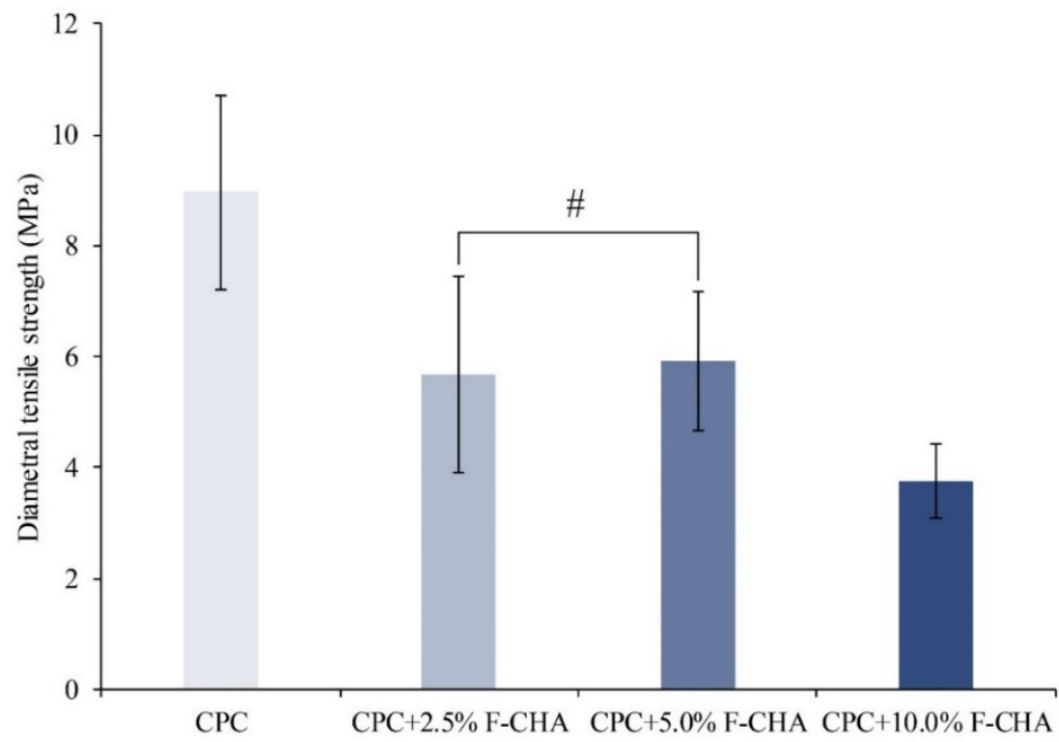

(b)

Figure 6. Compressive strength (a) and diametral tensile strength (b) of CPC composites with different ratios of ferulic acid-carbonated apatite nanorods after immersion in TBS for 1 day. Groups marked \# indicate non-significant differences $(n=6 ; p>0.05)$.

Because the compositions of F-CHA and CPC are similar, the reason behind the remarkable decrease in strength of the composites after F-CHA reinforcement was studied. The addition of the reinforcement to the CPC matrix may lead to aggregation of the FCHA nanorods on account of an increase in normal pressure. The formation of composite defects leads to stress concentration and a substantial decrease in strength. Therefore, CPC composites added with 10\% F-CHA to CPC may be more suitable for non-stress-bearing bone defect repair than other clinical applications requiring high strength.

3.3.3. SEM Images of the Fracture Surfaces and XRD Phase Identification of CPC + F-CHA Composites after Immersion for 1 Day

The CPC-only and CPC + F-CHA composites presented a coral reef-like structure after TBS immersion for 1 day (Figure 7). This structure is a type of apatite with an integrated surface. Each CPC + F-CHA composite immersed in TBS for 1 day was subjected to XRD analysis (Figure 8), and the results were compared with the standard files of JCPDS Nos. 09-0432, 77-0128, 72-0713, and 25-1137. The $2 \theta$ crystalline peaks of apatite are located at $25.90^{\circ}, 31.76^{\circ}, 32.19^{\circ}$, and $32.84^{\circ}$. The $2 \theta$ crystalline peak of DCPA occurs at $26.58^{\circ}$, and the 
crystalline peak of DCPD appears at $34.11^{\circ}$. These results show that, although the addition of F-CHA to CPC does not affect the formation of the apatite phase, the final CPC product is multi-phase, regardless of the presence or absence of F-CHA.

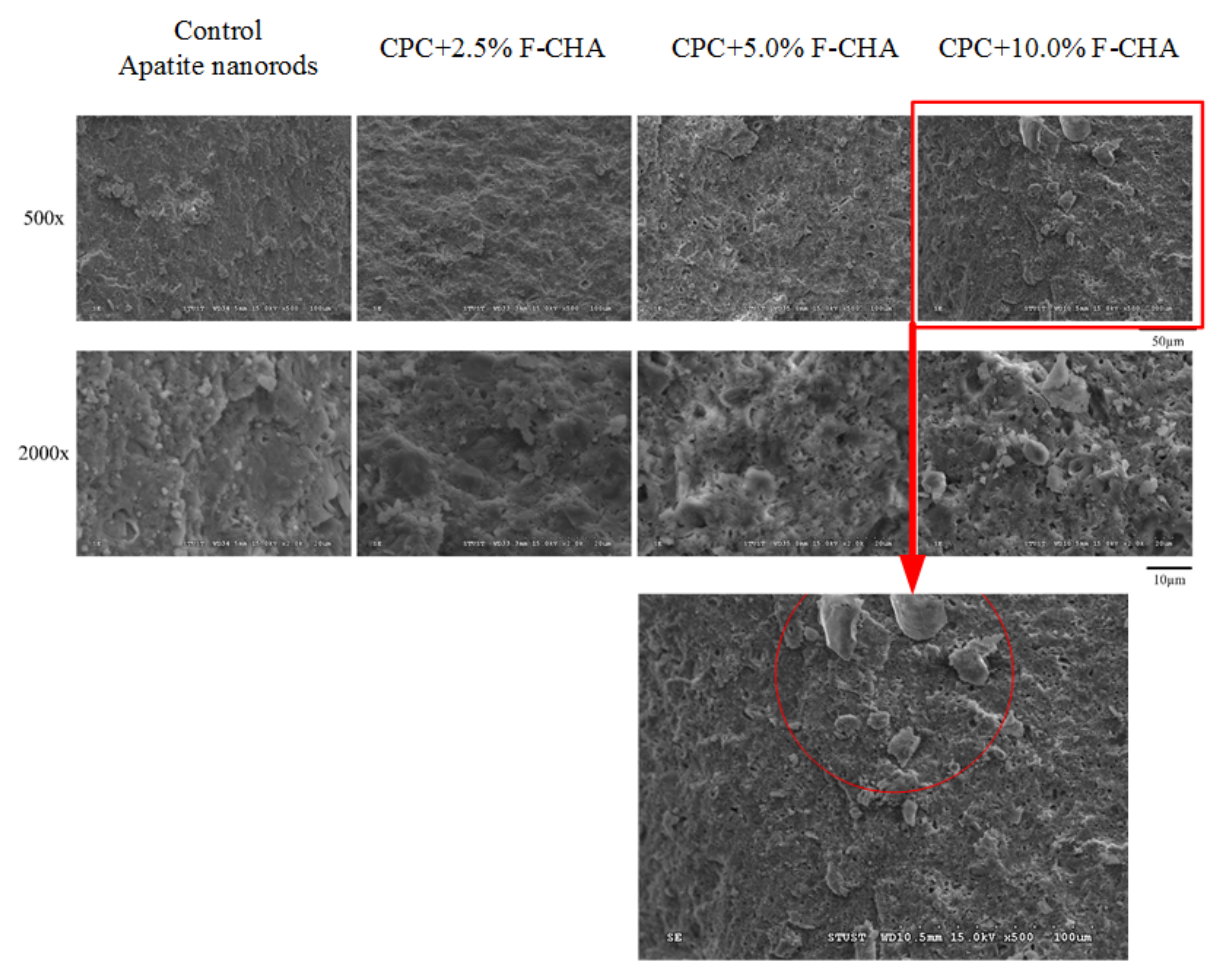

Figure 7. SEM images of fracture surfaces after compressive strength testing. CPC composites with different ratios of ferulic acid-carbonated apatite nanorods were measured after immersion in TBS for 1 day.

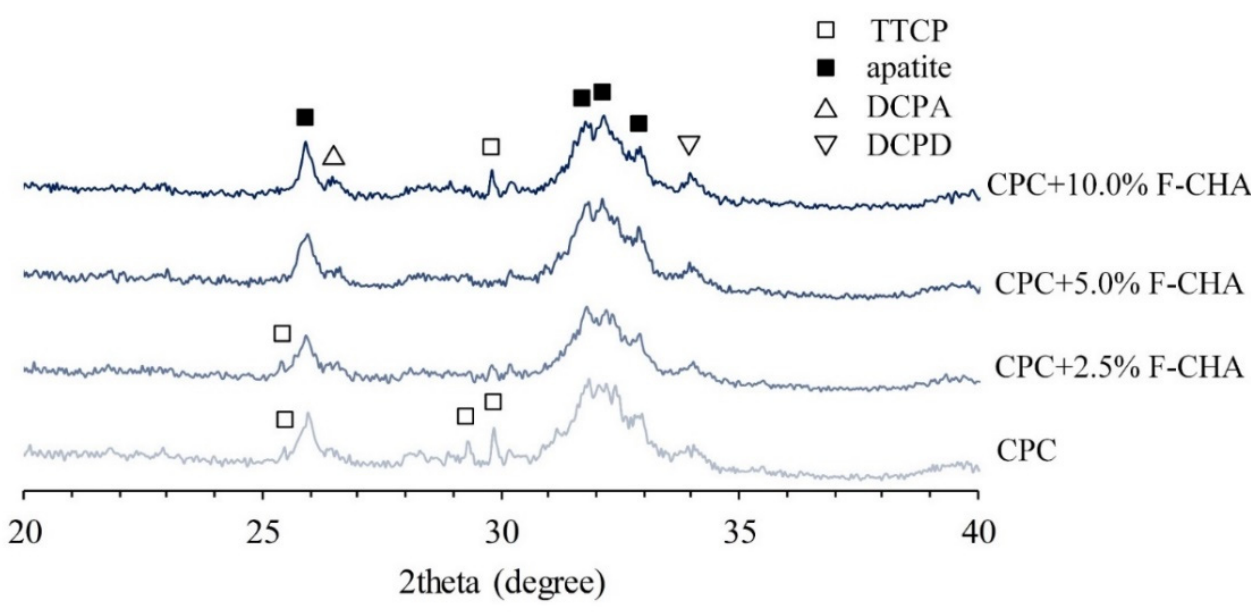

Figure 8. XRD phase identification of $\mathrm{CPC}$ composites with different ratios of ferulic acid-carbonated apatite nanorods after immersion in TBS for 1 day.

\subsubsection{Injection and Disintegration Tests of the CPC + F-CHA Composites in $\mathrm{ddH}_{2} \mathrm{O}$}

At present, $\mathrm{CPC}$ is defined as a combination of one or more calcium phosphates. When it is mixing with the hardening solution, it forms a slurry that can self-solidify or harden in situ at the bone defects. Therefore, one of the most important characteristics of CPC is that CPC can be formed in situ through a fluid-filled environment and still undergo a dissolution-precipitation hardening reaction. In this study, each group showed good injectability (Figure 9), and the CPC + F-CHA composites could be smoothly pushed out of 
the needle-free syringe without powder-liquid separation. After coming into contact with the solution for $1 \mathrm{~h}$, the composite presented a cylindrical shape without disintegration, thereby indicating that it has good anti-dispersion ability. This finding indicates that if the composite is applied to clinical implantation in the future, the necessary repair could be completed even if body fluids or blood are encountered during the operation.

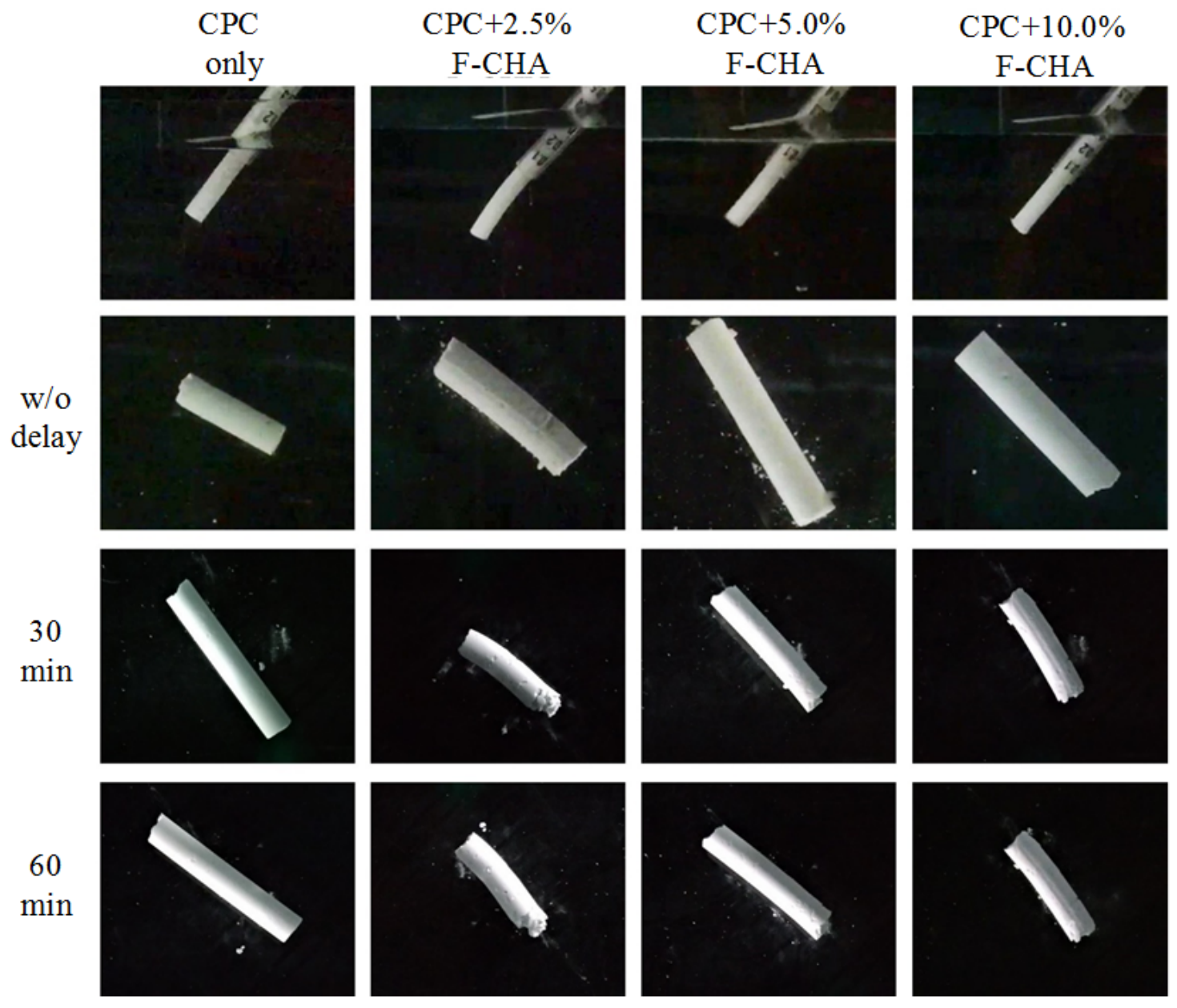

Figure 9. Injection and disintegration tests of CPC composites with different ratios of ferulic acid-carbonated apatite nanorods (CPC + F-CHA) after injection into $\mathrm{ddH}_{2} \mathrm{O}$.

3.4. Cytotoxicity toward L929, Cell Attachment, Proliferation, and Differentiation of D1 Cultured with $C P C+F-C H A$

3.4.1. Cell Viability and Morphologies of Sample Extract Culture with L929 Cells

According to the ISO-10993-5 standard, a $>30 \%$ reduction in cell viability indicates cytotoxic effects. The survival rate of cells cultured with the CPC + F-CHA composite extracts remained much higher than $70 \%$ regardless of the concentration of F-CHA that was added (Figure 10a), and the cell morphology of treated groups was similar to that of the control group (Figure 10b). Therefore, the CPC + F-CHA composites prepared in this work have no cytotoxicity. 


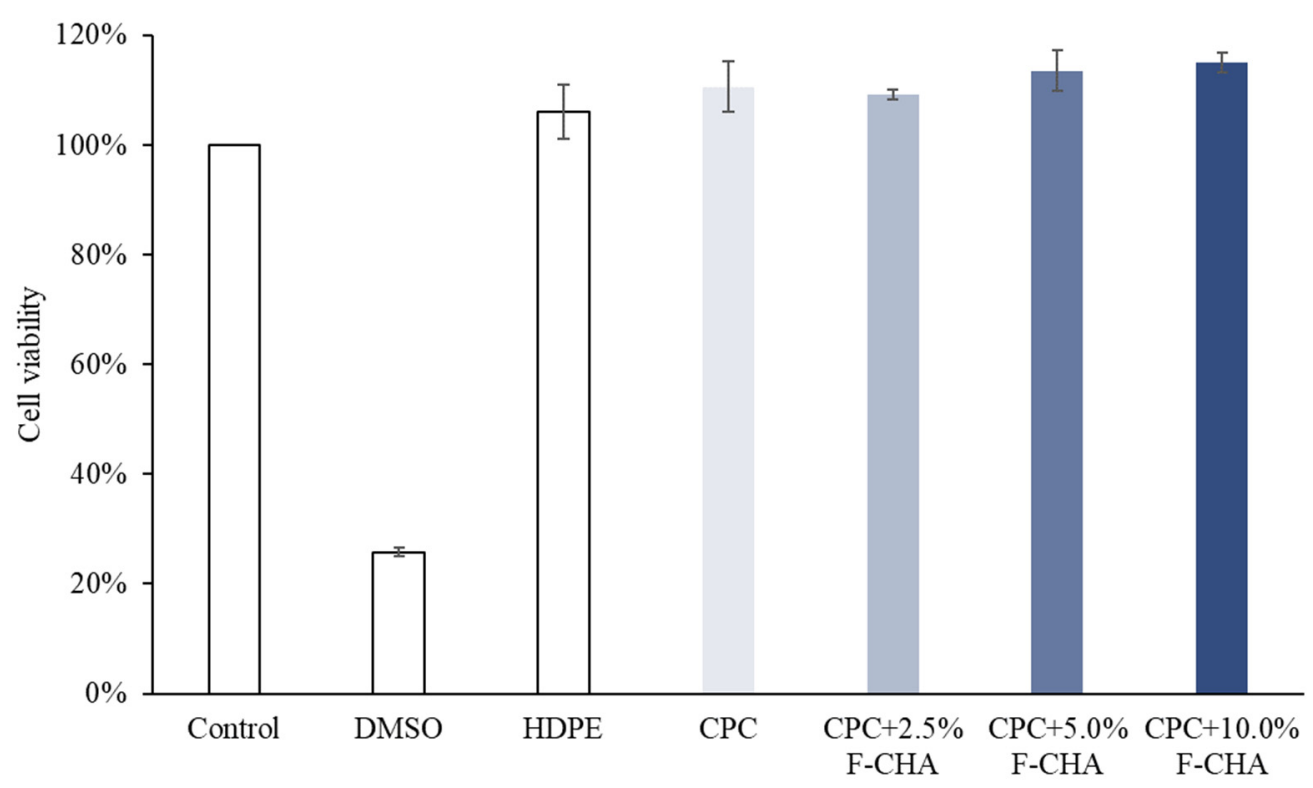

(a)

Control

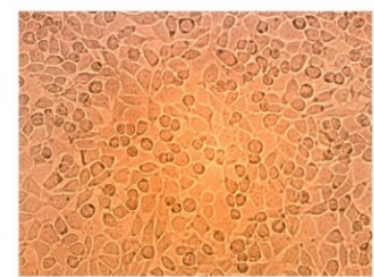

CPC

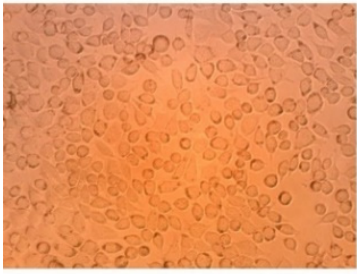

$\mathrm{CPC}+2.5 \% \mathrm{~F}-\mathrm{CHA}$
DMSO

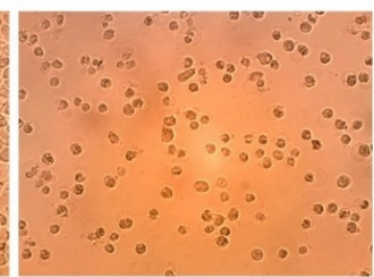

$\mathrm{CPC}+5.0 \% \mathrm{~F}-\mathrm{CHA}$

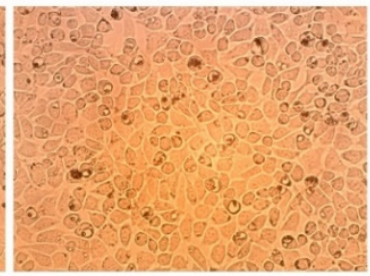

$\mathrm{CPC}+10.0 \% \mathrm{~F}-\mathrm{CHA}$

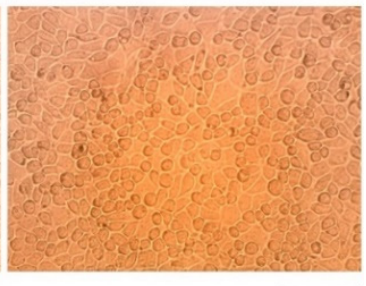

$\overline{100 \mu \mathrm{m}}$

(b)

Figure 10. Quantitative cell viability $(n=6)(\mathbf{a})$ and qualitative cell morphologies (b) of L929 cells cultured for $24 \mathrm{~h}$ in solutions of CPC only and CPC composites with different ratios of ferulic acid-carbonated apatite nanorods (F-CHA).

3.4.2. Morphology and ALP Activity of D1 Progenitor Bone Cells on Various CPC + F-CHA Composite Surfaces

D1 cells were exposed to the CPC + F-CHA composite materials for $1 \mathrm{~h}, 1$ day, and 2 days, and their resulting morphology was assessed by SEM (Figure 11). D1 cells cultured on the surface of each group for $1 \mathrm{~h}$ initially adhered to the composite surface; by comparison, the cells in the control CPC-only group showed a relatively spherical shape. Cells that were not flat-attached to the surface of the CPC-only showed that cell affinity was worse than other CPC + F-CHA groups. Therefore, the addition of F-CHA could promote the attachment of bone cells. After culturing for 1 day, the cells on the surface of each PC + F-CHA composite have well adhered to the composite surface, and pseudopodia began to protrude from the culture. D1 cells cultured for 2 days on the composite revealed good adherence and began to proliferate. 


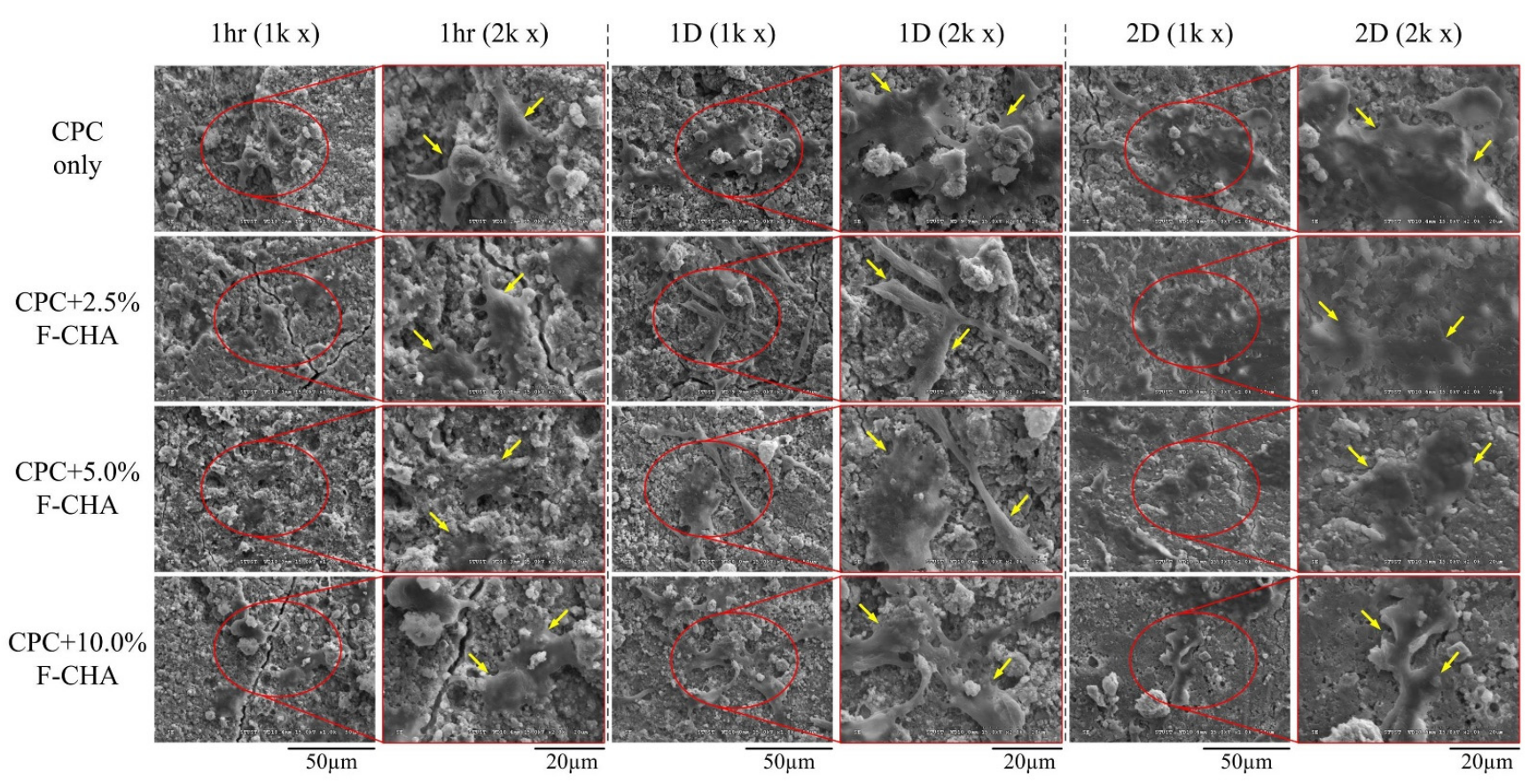

Figure 11. Morphologies of D1 progenitor bone cells cultured on the surfaces of CPC only and CPC composites with different ratios of ferulic acid-carbonated apatite nanorods for $1 \mathrm{~h}, 1$ day, and 2 days.

An ALP test was conducted to confirm whether the addition of different amounts of F-CHA to the CPC-matrix affects the bone mineralization ability of D1 cells. ALP is a phosphatase produced by bone cells, and its structure is composed of over 500 amino acids [27]. The enzyme can assist in the hydrolysis of phosphate monoesters and release phosphate to participate in bone matrix mineralization [28]. Because D1 cells secrete large amounts of ALP before entering mineralization, ALP content can be used to determine whether D1 cells begin to mineralize. The amount of ALP produced was divided by the number of cells to assess the ability of a single D1 cell to produce ALP (Figure 12). The amount of ALP in each group peaked on day 7 of culture and was maintained until day 10, thereby indicating that the D1 cells began to mineralize on day 7. The quantity of ALP in the CPC + F-CHA composites did not change significantly. On day 7, D1 cells in the group containing CPC $+10 \% \mathrm{~F}-\mathrm{CHA}$ began to secrete ALP at significantly higher levels compared with those in other groups. The results further showed that the higher the amount of F-CHA added, the greater the level of ALP secretion by D1 cells. Therefore, F-CHA does not affect the phase and biocompatibility of CPC, and the composite may be used as a carrier for sustained-release drugs to promote osteoprogenitor cell mineralization $[9,29,30]$.

CPCs are osteoconductive because they attract the osteoprogenitor cells to attach, proliferate, migrate and express phenotypes, leading to the formation of new bone. Osteoconduction also depends on the compositions and the strategy of incorporating different types of biomolecules, drugs, or ions to promote CPC bone conductivity and absorption after clinical implantation. With some improvements in CPC composites, these in vitro tests can be used for preliminary screening. However, the most reliable assessment of osteoconduction and bone resorption is still the implantation of bone defects in the body. Ferulic acids are natural polyphenols present in various fruits and are the active ingredient in many herbal medicines that are known to have the ability to suppress the fusion and apoptosis of mature osteoclasts $[29,31]$. Therefore, ferulic acid exhibited protective effects against osteoclastic activity. Moreover, ferulic acid promoted the in vitro osteogenic differentiation of blood mesenchymal stem cells by inhibiting micro340 to induce $\beta$-catenin expression through hypoxia [29]. In addition, the study also showed that the proper immobilization of heparin into a polypyrrole matrix could promote mesenchymal stem cell differentiation towards osteoblast lineage [32], thus increasing the levels of ALP, indicating mineralization 
processes. We hypothesize that the inclusion of certain quantities of F-CHA to CPC will regulate the initial release of ferulic acid and combine with the release of heparin after a period of extension in vitro. In contrast, the biological activity of the released ferulic acid and heparin is maintained. The ability to stimulate localized osteogenesis at controlled rates through the release of ferulic acid and CHA with heparin from CPC could provide a potential therapeutic strategy.

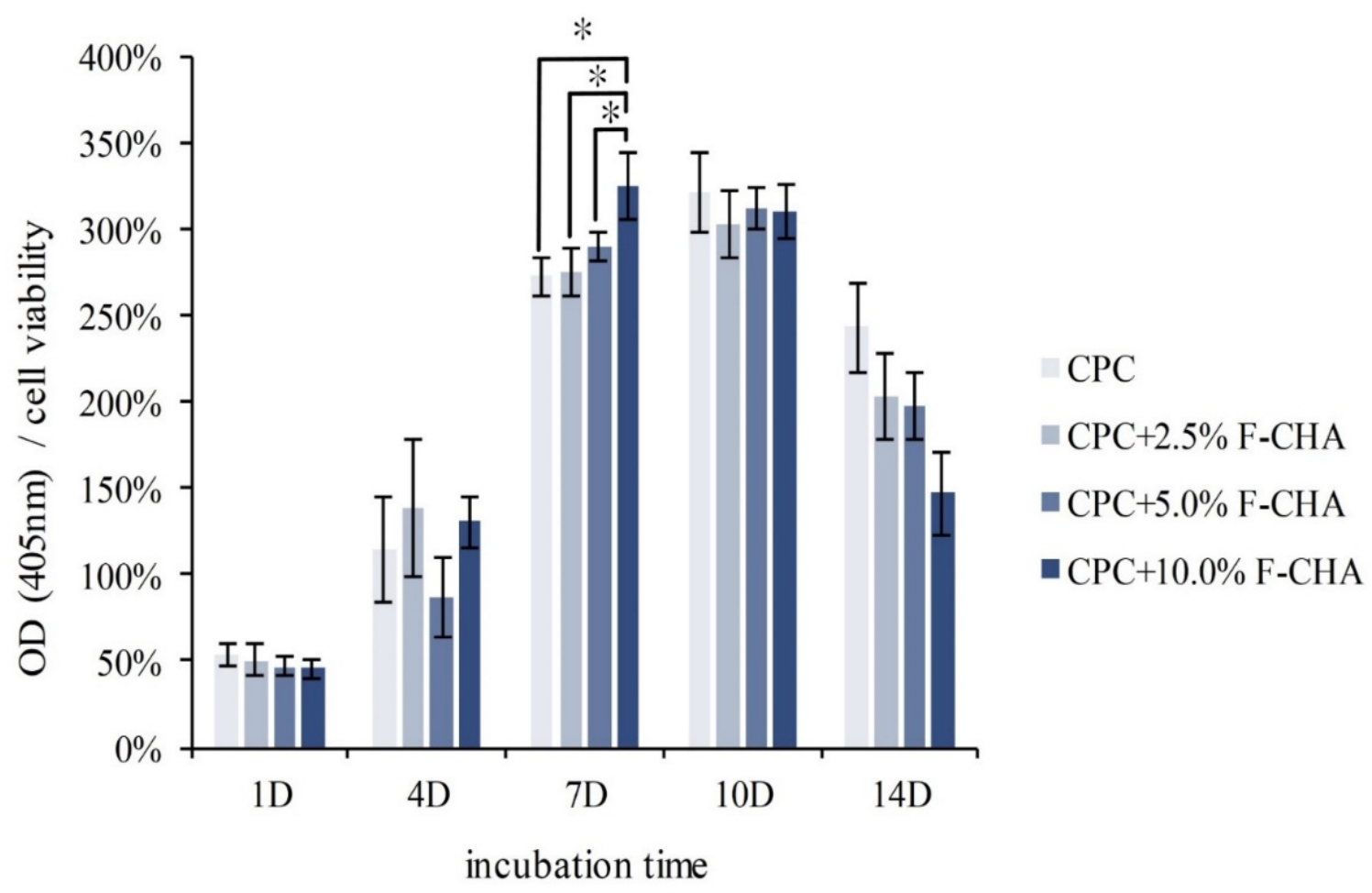

Figure 12. Semi-quantitative ALP activity of D1 cells seeded on CPC composites with different ratios of ferulic acidcarbonated apatite nanorods (CPC + F-CHA, $n=6)$. Groups marked * indicate statistically significant differences $(p<0.05)$.

\section{Conclusions}

The following conclusions may be drawn based on the results obtained in the present study:

1. L25K is a suitable mediator for impregnating bone, promoting ferulic acid, and compositing with $\mathrm{CPC}$ bone cement.

2. The release process of $\mathrm{CPC}+\mathrm{F}-\mathrm{CHA}$ composites shows three stages, including an early burst release from the composite surface, followed by the diffusion release of ferulic acid within the composites, and, finally, the slow release of the encapsulated drug. These findings prove that F-CHA may be an effective drug carrier.

3. The addition of F-CHA did not affect apatite formation. Increases in the addition of $\mathrm{F}-\mathrm{CHA}$ resulted in a decrease in the strength of the product obtained. The CS of the $\mathrm{CPC}+2.5,5.0 \% \mathrm{~F}-\mathrm{CHA} 2.5 \%$, and $5 \%$ additive groups were approximately $50 \mathrm{MPa}$; thus, these materials may be used as load-bearing devices. The group added with CPC $+10 \%$ F-CHA achieved a CS of only $30 \mathrm{MPa}$; while this strength is relatively low, the obtained material may still find applications in non-load bearing orthopedic restoration.

4. After $1 \mathrm{~h}$ of culture, D1 cells cultured in the CPC-only group retained their spherical shape, but the cell morphology of cells in all other experimental CPC + F-CHA groups was flat. These results demonstrate that ferulic acid can promote progenitor bone cell attachment. On the 10th day of D1 cell culture, the amount of ALP production in the $\mathrm{CPC}+10.0 \% \mathrm{~F}-\mathrm{CHA}$ group was significantly higher than that in other treatment 
groups. This finding indicates that the addition of F-CHA in CPC increases the ability of a single cell to secrete ALP.

5. It can be seen that the controlled amount of heparin can prepare uniform nanorodshaped CHA with good biocompatibility. The grafting of ferulic acid to CPC yielded a material that could be used as a slow-release drug carrier, thereby increasing the applicability of CPC in orthopedic tissue engineering.

Author Contributions: Conceptualization, K.-C.C., J.-C.C., C.-J.S. and W.-C.C.; Data curation, K.-C.C., J.-C.C., I.-T.C., S.-M.H., S.-M.L. and C.-L.K.; Formal analysis, K.-C.C., J.-C.C., I.-T.C., S.-M.H., S.-M.L., C.-L.K. and W.-C.C.; Funding acquisition, W.-C.C.; Investigation, K.-C.C., J.-C.C., I.-T.C., S.-M.H., S.-M.L., C.-L.K., Y.-S.S. and W.-C.C.; Methodology, Y.-S.S., C.-J.S. and W.-C.C.; Project administration, W.-C.C.; Resources, C.-L.K., Y.-S.S., C.-J.S. and W.-C.C.; Supervision, W.-C.C.; Validation, W.-C.C.; Visualization, W.-C.C.; Writing—original draft, K.-C.C., J.-C.C., S.-M.H., S.-M.L., C.-J.S. and W.-C.C.; Writing-review and editing, K.-C.C., C.-L.K., Y.-S.S., C.-J.S. and W.-C.C. All authors have read and agreed to the published version of the manuscript.

Funding: This research was majorly supported by the Ministry of Science and Technology, Taiwan (grant numbers MOST 109-2221-E-035-43, 109-2622-E-035-014-CC2, 108-2221-E-035-043 and 105-2221E-035-021-MY3) and was funded partly by KMU research project (KMUH109-9R56).

Institutional Review Board Statement: Not applicable.

Informed Consent Statement: Not applicable.

Data Availability Statement: The data presented in this study are available on request from the corresponding author.

Acknowledgments: The authors acknowledge and appreciate the Precision Instrument Support Center of Feng Chia University, which provided the fabrication and measurement facilities. The assistance of the participants in this research is also acknowledged.

Conflicts of Interest: The authors declare no conflict of interest.

\section{References}

1. Melville, A.J.; Harrison, J.; Gross, K.A.; Forsythe, J.S.; Trounson, A.O.; Mollard, R. Mouse embryonic stem cell colonisation of carbonated apatite surfaces. Biomaterials 2006, 27, 615-622. [CrossRef] [PubMed]

2. Frank-Kamenetskaya, O.; Kol'tsov, A.; Kuz'mina, M.; Zorina, M.; Poritskaya, L. Ion substitutions and non-stoichiometry of carbonated apatite-(CaOH) synthesised by precipitation and hydrothermal methods. J. Mol. Struct. 2011, 992, 9-18. [CrossRef]

3. Haung, S.-M.; Chen, J.-C.; Chang, K.-C.; Ko, C.-L.; Lin, D.-J.; Chen, W.-C. Synthesis of nanorod apatites with templates at critical micelle concentrations and in vitro evaluation of cytotoxicity and antimicrobial activity. J. Asian Ceram. Soc. 2021, 1-12. [CrossRef]

4. Haider, A.; Haider, S.; Han, S.S.; Kang, I.-K. Recent advances in the synthesis, functionalization and biomedical applications of hydroxyapatite: A review. RSC Adv. 2017, 7, 7442-7458. [CrossRef]

5. Xiao, X.; He, D.; Liu, F.; Liu, R. Preparation and characterization of hydroxyapatite/chondroitin sulfate composites by biomimetic synthesis. Mater. Chem. Phys. 2008, 112, 838-843. [CrossRef]

6. El-Hamshary, H.; El-Naggar, M.E.; El-Faham, A.; Abu-Saied, M.A.; Ahmed, M.K.; Al-Sahly, M. Preparation and Characterization of Nanofibrous Scaffolds of Ag/Vanadate Hydroxyapatite Encapsulated into Polycaprolactone: Morphology, Mechanical, and In Vitro Cells Adhesion. Polymers 2021, 13, 1327. [CrossRef]

7. Sadeghinia, A.; Davaran, S.; Salehi, R.; Jamalpoor, Z. Nano-hydroxy apatite/chitosan/gelatin scaffolds enriched by a combination of platelet-rich plasma and fibrin glue enhance proliferation and differentiation of seeded human dental pulp stem cells. Biomed. Pharmacother. 2019, 109, 1924-1931. [CrossRef]

8. Kolanthai, E.; Sindu, P.A.; Arul, K.T.; Chandra, V.S.; Manikandan, E.; Kalkura, S.N. Agarose encapsulated mesoporous carbonated hydroxyapatite nanocomposites powder for drug delivery. J. Photochem. Photobiol. B Biol. 2017, 166, 220-231. [CrossRef]

9. Du, K.; Li, Z.; Fang, X.; Cao, T.; Xu, Y. Ferulic acid promotes osteogenesis of bone marrow-derived mesenchymal stem cells by inhibiting microRNA-340 to induce $\beta$-catenin expression through hypoxia. Eur. J. Cell Biol. 2017, 96, 496-503. [CrossRef]

10. Folwarczna, J.; Zych, M.; Burczyk, J.; Trzeciak, H.; Trzeciak, H. Effects of Natural Phenolic Acids on the Skeletal System of Ovariectomized Rats. Planta Med. 2009, 75, 1567-1572. [CrossRef] [PubMed]

11. Carey, L.E.; Xu, H.H.; Simon, C.G.; Takagi, S.; Chow, L.C.; Simonjr, C. Premixed rapid-setting calcium phosphate composites for bone repair. Biomaterials 2005, 26, 5002-5014. [CrossRef] [PubMed]

12. Ko, C.-L.; Chen, J.-C.; Tien, Y.-C.; Hung, C.-C.; Wang, J.-C.; Chen, W.-C. Osteoregenerative capacities of dicalcium phosphate-rich calcium phosphate bone cement. J. Biomed. Mater. Res. A 2014, 103, 203-210. [CrossRef] [PubMed] 
13. Wu, M.; Wang, T.; Zhang, Y. Premixed tricalcium silicate/sodium phosphate dibasic cements for root canal filling. Mater. Chem. Phys. 2021, 257, 123682. [CrossRef]

14. Xu, H.H.; Wang, P.; Wang, L.; Bao, C.; Chen, Q.; Weir, M.D.; Chow, L.C.; Zhao, L.; Zhou, X.; Reynolds, M.A. Calcium phosphate cements for bone engineering and their biological properties. Bone Res. 2017, 5, 17056. [CrossRef]

15. Fosca, M.; Rau, J.V.; Uskoković, V. Factors influencing the drug release from calcium phosphate cements. Bioact. Mater. 2021. [CrossRef]

16. Taheri, M.M.; Kadir, M.R.A.; Shokuhfar, T.; Hamlekhan, A.; Shirdar, M.R.; Naghizadeh, F. Fluoridated hydroxyapatite nanorods as novel fillers for improving mechanical properties of dental composite: Synthesis and application. Mater. Des. 2015, 82, 119-125. [CrossRef]

17. Chen, W.-C.; Cheng, I.-T.; Chang, K.-C.; Haung, S.-M.; Chen, J.-C.; Shih, C.-J. Heparin as a biomimetic template on nanoapatite rods with tunable aspect ratio: Synthesis and biocompatibility. J. Aust. Ceram. Soc. 2021, 57, 825-834. [CrossRef]

18. Chen, W.-C.; Lin, J.-H.C.; Ju, C.-P. Transmission electron microscopic study on setting mechanism of tetracalcium phosphate/dicalcium phosphate anhydrous-based calcium phosphate cement. J. Biomed. Mater. Res. 2003, 64, 664-671. [CrossRef] [PubMed]

19. Wang, J.-C.; Ko, C.-L.; Hung, C.-C.; Tyan, Y.-C.; Lai, C.-H.; Chen, W.-C.; Wang, C.-K. Deriving fast setting properties of tetracalcium phosphate/dicalcium phosphate anhydrous bone cement with nanocrystallites on the reactant surfaces. J. Dent. 2010, 38, 158-165. [CrossRef]

20. Fleet, M.E.; Liu, X. Coupled substitution of type A and B carbonate in sodium-bearing apatite. Biomaterials 2007, 28, 916-926. [CrossRef]

21. Deng, Y.; Sun, Y.; Chen, X.; Zhu, P.; Wei, S. Biomimetic synthesis and biocompatibility evaluation of carbonated apatites template-mediated by heparin. Mater. Sci. Eng. C 2013, 33, 2905-2913. [CrossRef]

22. Ternent, L.; Mayoh, D.; Lees, M.; Davies, G.-L. Heparin-stabilised iron oxide for MR applications: A relaxometric study. J. Mater. Chem. B 2016, 4, 3065-3074. [CrossRef]

23. Lafon, J.P.; Champion, E.; Bernache-Assollant, D. Processing of AB-type carbonated hydroxyapatite $\mathrm{Ca}_{10-x}\left(\mathrm{PO}_{4}\right)_{6-x}\left(\mathrm{CO}_{3}\right)_{\mathrm{x}}$ $(\mathrm{OH})_{2-x-2 y}\left(\mathrm{CO}_{3}\right) y$ ceramics with controlled composition. J. Eur. Ceram. Soc. 2008, 28, 139-147. [CrossRef]

24. Liao, J.; Li, Y.; Li, H.; Liu, J.; Xie, Y.; Wang, J.; Zhang, Y. Preparation, bioactivity and mechanism of nano-hydroxyapatite/sodium alginate/chitosan bone repair material. J. Appl. Biomater. Funct. Mater. 2018, 16, 28-35. [CrossRef]

25. Zhao, X.; Ng, S.; Heng, B.C.; Guo, J.; Ma, L.; Tan, T.; Ng, K.W.; Loo, S.C.J. Cytotoxicity of hydroxyapatite nanoparticles is shape and cell dependent. Arch. Toxicol. 2012,87, 1037-1052. [CrossRef]

26. Khairoun, I.; Boltong, M.G.; Driessens, F.C.M.; Planell, J.A. Effect of calcium carbonate on clinical compliance of apatitic calcium phosphate bone cement. J. Biomed. Mater. Res. 1997, 38, 356-360. [CrossRef]

27. Sharma, U.; Pal, D.; Prasad, R. Alkaline Phosphatase: An Overview. Indian J. Clin. Biochem. 2014, 29, 269-278. [CrossRef]

28. Du, K.; Fang, X.; Li, Z. Ferulic acid suppresses interleukin-1 $\beta$-induced degeneration of chondrocytes isolated from patients with osteoarthritis through the SIRT1/AMPK/PGC-1 $\alpha$ signaling pathway. Immun. Inflamm. Dis. 2021. [CrossRef]

29. Chen, J.-C.; Chen, C.-H.; Chang, K.-C.; Liu, S.-M.; Ko, C.-L.; Shih, C.-J.; Sun, Y.-S.; Chen, W.-C. Evaluation of the Grafting Efficacy of Active Biomolecules of Phosphatidylcholine and Type I Collagen on Polyether Ether Ketone: In Vitro and In Vivo. Polymers 2021, 13, 2081. [CrossRef]

30. Liang, J.; Li, P.; Wang, Q.; Liao, S.; Hu, W.; Zhao, Z.; Li, Z.; Yin, B.; Mao, N.; Ding, L.; et al. Ferulic acid promotes bone defect repair after radiation by maintaining the stemness of skeletal stem cells. Stem Cells Transl. Med. 2021. [CrossRef]

31. Hou, T.; Zhang, L.; Yang, X. Ferulic acid, a natural polyphenol, protects against osteoporosis by activating SIRT1 and NF- $\mathrm{KB}$ in neonatal rats with glucocorticoid-induced osteoporosis. Biomed. Pharmacother. 2019, 120, 109205. [CrossRef] [PubMed]

32. Moreno, J.S.; Sabbieti, M.G.; Agas, D.; Marchetti, L.; Panero, S. Polysaccharides immobilized in polypyrrole matrices are able to induce osteogenic differentiation in mouse mesenchymal stem cells. J. Tissue Eng. Regen. Med. 2012, 8, 989-999. [CrossRef] [PubMed] 